Illinois State University

ISU ReD: Research and eData

Theses and Dissertations

6-3-2014

\title{
An Analysis Of Program Evaluation In Community College Learning Assistance Centers
}

Doug Franklin

Illinois State University, dougalanfranklin@gmail.com

Follow this and additional works at: https://ir.library.illinoisstate.edu/etd

Part of the Educational Assessment, Evaluation, and Research Commons, Higher Education Administration Commons, and the Higher Education and Teaching Commons

\section{Recommended Citation}

Franklin, Doug, "An Analysis Of Program Evaluation In Community College Learning Assistance Centers" (2014). Theses and Dissertations. 197.

https://ir.library.illinoisstate.edu/etd/197

This Dissertation is brought to you for free and open access by ISU ReD: Research and eData. It has been accepted for inclusion in Theses and Dissertations by an authorized administrator of ISU ReD: Research and eData. For more information, please contact ISUReD@ilstu.edu. 


\title{
AN ANALYSIS OF PROGRAM EVALUATION IN COMMUNITY COLLEGE LEARNING ASSISTANCE CENTERS
}

\author{
Doug A. Franklin
}

122 Pages

August 2014

Learning assistance centers exist in varied formats at many colleges and provide services to support the educational mission such as tutoring, support for special needs students, study skills instruction, writing or math instruction. This study seeks to add to the small body of research on evaluation measures used within learning assistance centers and the program evaluation practices of such centers by determining the prevalence of program evaluation and what measures learning assistance directors perceive they should be using in the evaluation of their program compared to those actually being used?

Learning assistance center directors at 61 public two-year institutions, out of a nationwide sample of 226, responded to a survey and 43 of those respondents indicated program evaluation had taken place within their center. Those 43 rated their level of agreement, in terms of current practice and whether they thought it should be the current practice, with a number of statements pertaining to program evaluation within their centers and to the use of various evaluation measures.

A descriptive analysis of the structures and range of services offered by learning assistance centers was performed as well as a descriptive analysis of the conditions and practices for program evaluation and of the potential evaluation measures. Descriptive 
statistics are presented for each item and t-test comparisons of the composite group means were performed to compare the current state of evaluation to the state desired by the learning assistance directors.

It was found that $70.5 \%$ of the respondents indicated they had engaged in program evaluation within the last two years. These evaluations often include multiple measures and the directors believe the measures are appropriate. The evaluation plans in use also seem to be based on many of the "best practices" of program evaluation found in the literature. One area of discord was the inclusion of students in evaluation planning as it did not happen as frequently as the directors desired. Although alignment between the evaluation and the center's mission was rated high by most, the responses suggest that an "unspoken” mission of assisting at-risk students may require further consideration in the current practice. 
AN ANALYSIS OF PROGRAM EVALUATION IN COMMUNITY COLLEGE

LEARNING ASSISTANCE CENTERS

\author{
DOUG A. FRANKLIN
}

A Dissertation Submitted in Partial

Fulfillment of the Requirements for the Degree of

DOCTOR OF EDUCATION

Department of Educational Administration and Foundations

ILLINOIS STATE UNIVERSITY

2014 
AN ANALYSIS OF PROGRAM EVALUATION IN COMMUNITY COLLEGE LEARNING ASSISTANCE CENTERS

DOUG A. FRANKLIN

COMMITTEE MEMBERS:

James C. Palmer, Chair

Lydia Kyei-Blankson

Mohamed Nur-Awaleh

Bob Blankenberger 


\section{ACKNOWLEDGMENTS}

This has been a long road and I have to start by thanking my wife, Sara, for her patience and support. Also, my thanks and love to my son and daughter, Dominic and Samantha, who have had to give up some time with their Daddy while he locked himself away on the computer.

I am indebted to Dr. Jim Palmer for his support and guidance when he graciously agreed to step in as my new chair. Dr. Lydia Kyei-Blankson and Dr. Mohamed NurAwaleh provided useful advice and some probing questions that improved the quality of the proposal leading up to this final product as well.

Dr. Bob Blankenberger has been a mentor to me both in this journey as well as in my professional career and, although this work concludes my formal education, I know that our future collaboration will result in continuous learning and growth.

D.A.F. 


\section{CONTENTS}

Page

ACKNOWLEDGMENTS

CONTENTS

TABLES $\quad$ iv

CHAPTER

I. BACKGROUND AND STATEMENT OF THE PROBLEM 1

The Research Problem $\quad 2$

The Current Study and Research Questions 3

Significance of the Study $\quad 4$

Learning Assistance Centers and Educational Attainment 8

Postsecondary Educational Attainment and the Economy 12

Current Limitations in the Research of Learning Assistance $\begin{array}{ll}\text { Centers } & 14\end{array}$

$\begin{array}{ll}\text { Methodology } & 15\end{array}$

$\begin{array}{ll}\text { Definitions } & 17\end{array}$

II. REVIEW OF THE LITERATURE 19

$\begin{array}{ll}\text { Learning Assistance Centers } & 19\end{array}$

Challenges Facing Learning Assistance Centers in Community Colleges 20

Assessment of Learning Assistance Centers 26

The Assessment Movement 27

The Lack of an Assessment Movement in Developmental Education and Learning Assistance Centers 28

What to Measure? 30

$\begin{array}{ll}\text { Program Evaluation } & 40\end{array}$

Alignment with Mission/Goals $\quad 40$

Stakeholder Involvement $\quad 41$

Appropriate Data Use $\quad 47$ 
Adequate Resources $\quad 48$

Summary 49

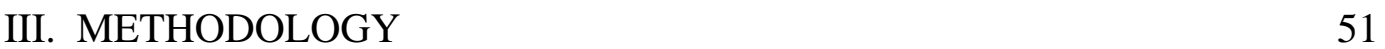

Sample Selection $\quad 52$

Design of the Survey Instrument 56

Analysis of the Survey Responses 58

Limitations of the Present Study $\quad 59$

$\begin{array}{lr}\text { IV. RESULTS } & 60\end{array}$

Section One - Contextual Information 60

$\begin{array}{ll}\text { Staffing } & 61\end{array}$

Funding 63

Learning Assistance Center Services $\quad 64$

Section Two - Practices in Program Evaluation 65

Section Three - Potential Evaluation Measures 76

V. DISCUSSION AND CONCLUSIONS 84

Organizational Context of the Responding Centers 85

Staffing $\quad 86$

Availability of Data $\quad 86$

Limited Control $\quad 87$

On the Margins? $\quad 88$

Findings Concerning Evaluation Practices and Measures 88

Strengths and Weaknesses of LAC Program Evaluation 89

$\begin{array}{ll}\text { Implications for Practice } & 91\end{array}$

Student Engagement in Program Evaluation 91

Attention to Student Clients with Greatest Needs 93

Resources for Effective Program Evaluation 95

$\begin{array}{ll}\text { Future Directions } & 96\end{array}$

$\begin{array}{ll}\text { REFERENCES } & 100\end{array}$

APPENDIX A: Survey Instrument 111

APPENDIX B: Letter Sent to Learning Assistance Center Directors 120 


\section{TABLES}

Table

Page

1. 2013 Retention (Fall 2012 Cohort) and Three-Year Graduation (Fall 2010 Cohort) Rates

2. IPEDS EZ Group Parameters Used to Identify Sample

3. Surveys and Variables Used to Identify Sample

4. Staffing Levels in Respondents’ Learning Assistance Centers

5. Prevalence of Services Offered in Learning Assistance Centers

6. t-Test: Paired Two Sample for Means Comparing Actual Practice to LAC Director's Perception

7. Mean and Distribution of Responses for "Does Reflect" and "Should Reflect" Statement Pairs

8. Statement Pairs Where Both Means Were Greater Than Three

9. Statement Pairs Where Both Means Were Less Than Three

10. t-Test: Paired Two Sample for Means Comparing Actual Use to LAC Directors' Preference for the Use of Potential Evaluation Measures

11. Mean and Distribution of Responses for "Actual Use" and "Should Use" of Potential Evaluation Measures

12. Evaluation Measures Where the "Did Use" and "Should Use" Responses Were Both Greater Than Three 


\section{CHAPTER I}

\section{BACKGROUND AND STATEMENT OF THE PROBLEM}

Learning assistance centers exist in varied formats at most community colleges and many four-year colleges and universities. Such centers provide a wide array of services in support of the educational mission of the institution. A learning assistance center, for the purposes of this study, is best described as "a designated physical location on campus that provides an organized, multifaceted approach to offering comprehensive academic enhancement activities outside of the traditional classroom setting to the entire college community” (Arendale, 2007 p. 22). Services provided may include tutoring, study groups, support for special needs students, study skills instruction, writing or math skills instruction, computer assistance, and similar services. How such centers are structured and staffed can vary greatly from one institution to another. For example, professional staff may be employed at one institution or student-peer tutors may be utilized to provide tutoring instruction at another institution.

There is a small and limited literature on learning assistance centers and the evaluation of their effectiveness. Authors have written about the existence and structure of such centers (Consolvo, 2002; Stern, 2001) and they have written about the work that these centers do and the challenges they face (Perin, 2004; Williams, 2002). Some authors have offered recommendations for learning assistance centers on how to engage 
in assessment and evaluation (Clark-Thayer, 1995; Maxwell, 1979) while others have criticized the current state of assessment and evaluation in these centers (Simpson, Hynd, Nist, \& Burrell, 1997). Criticisms include that such work is often focused solely on a single learning assistance center where the author is employed (Boughan, 1996; Robert \& Thomson, 1994) and that research focuses on a single technique (Hadwin \& Winne, 1996) instead of the broad array of services typically offered in a learning assistance center.

\section{The Research Problem}

Learning assistance centers are engaged in multiple instructional activities that include one-on-one and group interaction with students. Center staff may be engaged in active, planned, assessment activities to determine the needs of the students and whether instruction or techniques are having a positive impact, or staff may only be engaging in assessment informally or not at all. Similarly, the information gathered from assessment activities, if any, may be purposefully collected for a formal evaluation of the center and its work, or such evaluation may be carried out informally or not at all. It is through the practice of assessment and program evaluation that a learning assistance center can determine areas needing improvement and how effective the center and its staff are in addressing those needs.

The improvement of learning assistance centers, specifically, is important for two primary reasons. First, learning assistance centers can play a role in improving the number of adults holding postsecondary credentials and therefore strengthening the nation's workforce and economy. Second, colleges and universities are under extreme financial pressures and there is a risk of diminished funding or the outright elimination of 
learning assistance programming unless the value of the center can be demonstrated. However, there is sparse information in the literature about whether learning assistance centers are evaluating their progress in helping students to succeed, and therefore providing a return on investment to the institution, and there is also sparse information about what the current practices look like in those centers that are undergoing evaluation. This study is designed to address those two gaps in the current literature.

\section{The Current Study and Research Questions}

The purpose of this study is to add to the small body of research on evaluation measures used within learning assistance centers and the program evaluation practices of such centers by answering the following research questions through an exploratory study based on a survey of staff who lead community college learning assistance centers:

1. How prevalent is the practice of program evaluation in community college learning assistance centers? That is, what proportion of community college learning assistance centers have conducted an evaluation of their services in the past two years?

2. What practices and evaluation measures do community college learning assistance directors perceive they should be using in the evaluation of their programs and what practices and evaluation measures are actually being used? Is there a gap between the directors' perceptions of what practices and evaluation measures they are using and what practices and evaluation measures they should be using?

In other words, is program evaluation taking place? If so, what practices and measures are being used and do the administrators of the centers feel they are the appropriate 
practices and measures? This study does not seek to evaluate the outcomes of learning assistance centers, only to examine the current state of program evaluation as it exists in the centers included in this study.

\section{Significance of the Study}

Examining the current state of evaluation of learning assistance centers is important for two reasons. First, if institutions are making choices about which programs to cut or by how much during challenging fiscal years then having valid and reliable data on the impact that a learning assistance center can have on student retention and success is important. Second, the staff of the learning assistance centers also need access to valid and reliable data to gauge their own effectiveness in their goal of assisting students. During the author's own experience in a learning assistance center, the state grant that had funded the center was eliminated and the institution then decided to continue to fund the center. However, the institution now took a greater interest in trying to determine the value of the center. The first response from the institutional research office was to examine the grade point averages (GPAs) of those students who utilized the services of the center and compare those to the GPAs of students who had not accessed the center. However, as the staff within the center attempted to explain, those who use the services of the center do so because they are struggling. A large percentage of them are also enrolled in developmental coursework. Therefore it should not be surprising that many of these students did not perform well in their courses. Course grades are not a valid measure of the effectiveness of services within a learning assistance center as will be discussed in greater detail. Center staff offered arguments against the use of course grades but struggled to identify alternative methods of assessment. There was no 
opposition to the idea of assessing our work or evaluating outcomes, but there was no agreement on how to move forward. There was also a perception that this process would have an impact on the future funding of the center, that the intention was to demonstrate the worth of the center to the outside rather than to improve performance or services for students.

The desire to improve through the processes of assessment and evaluation can serve many internal needs for learning assistance centers, but external accountability is an ever-present and increasingly important factor that cannot be ignored. External pressures on higher education have risen dramatically in the wake of the current recession and budget shortfalls (Hebel, 2010). The public, and many lawmakers, are concerned about how tax money is being spent, suggesting that cuts are needed to balance the budget in many states such as Illinois (Mercer, 2010), California (Glenn, Laster, Miller, \& Schmidt, 2010; Spielman, 2010), and New Jersey (Tilsley, 2010). No sector is being overlooked in these discussions, and higher education is typically targeted more prevalently than K-12 education (Thrift, 2010). A postsecondary education is not compulsory and there is some debate as to whether and to what extent higher education serves a public good versus a personal, private good (Gibbs, 2001). Those who believe higher education serves as a private good instead of a public one feel that public funding should be diminished. There is a perception among some members of the public and the legislature that spending on student services functions amounts to waste compared to spending on core functions such as classroom instruction (Ehrenberg, 2012).

What is, and is not, a core operating function beyond instruction provided by faculty is certainly a difficult question to answer, and one that will likely provoke some 
disagreement. One area that is often a primary target in budget reductions is student affairs (Romano, Hanish, Phillips, \& Waggoner, 2010). Student affairs is a broad term that encompasses many functions including recruitment, advising, student life, and learning assistance centers, among other functions. Trying to determine how effective such services are can be more difficult in some cases than others. The number of students served may be a useful metric for recruiters or those in charge of student life activities, but may be of limited use when evaluating an advisor or a tutor. For example, an advisor who directs 100 students into the wrong math course is not as effective as an advisor who only counsels 10 students but places them appropriately. Assessment of student usage, student satisfaction, student performance, faculty satisfaction, and retention rates are all possible evaluation criteria and have been used to some extent across the nation (Maxwell, 1979). Each criterion presents its own problems in terms of confounding variables. A headcount of students served does offer one level of insight into the performance of a center. Obviously, if few or no students attend, then the center is not an effective program. However, headcounts do not provide any information about the impact that such services have on students and whether these services help to promote academic success.

Academic success is often correlated with grades or a GPA. If a tutor is successful, the student receiving assistance should do well, for example. However, the tutor is not the only one influencing the outcome. There is a classroom instructor, obviously, but ultimately it is the student who holds the most influence over his/her own performance. If the student did not open the book until the night before the test and then met with the tutor the morning of the test, can we blame the tutor for a failing grade? 
Such confounding issues make assessment difficult, and the response can be to look for an "easy" measure. Even though headcounts may not be an effective measure, they are certainly fairly easy to measure, so it is not surprising that such metrics are often relied upon heavily when a program must demonstrate its impact on the campus.

Using GPAs and course completion rates to determine the effectiveness of academic assistance can be problematic because of the varying characteristics of those who seek assistance (Maxwell, 1979). It is common to find a number of students enrolled in courses where the students lack required pre-requisites (i.e., foundation courses required before higher level coursework) and therefore seek assistance because of their weak backgrounds (Oudenhoven, 2002). Based on the author's experience this may happen due to institutional policies, improper advising, or lobbying from the student to be granted exemptions. Assistance center staff have no control or influence regarding the classroom environment, the skill of the instructor or student, or the motivation and persistence of the student. Academic gains may not translate into academic success for students starting from such a disadvantaged knowledge base. Consider the example of the staff member who counsels a student in an arithmetic class to drop an economics class. While many would agree that the staff member was successful in assisting the student, a subsequent drop in course completion rate will be recorded.

If program evaluation is being done strictly to satisfy external stakeholders such as legislators or budget officers, there may be a temptation to look for the most direct measures such as headcounts and GPAs of students that received assistance (Burke \& Serban, 1998; Maxwell, 1979). On the other hand, if program evaluation is being performed to aid the staff in determining their own effectiveness and to refine their 
practices, a deeper and more robust set of measures and methods should be employed (Simpson, Hynd, Nist, \& Burrell, 1997). Program evaluation schema that informs the center staff about whether they are effective in their work with students would be beneficial to the staff and allow both the staff and students to achieve higher levels of success (Hadden \& Davies, 2002). Why should learning assistance centers be concerned with improvement though?

\section{Learning Assistance Centers and Educational Attainment}

One reason that learning assistance centers should be concerned with improvement is the potential role that they can play in increasing educational attainment. The connection between education and workforce development was brought into the spotlight when President Obama indicated a need for a significant increase in the proportion of the adult population in this country who hold a college degree (Field, 2009). The United States has lost its competitive edge in this area and has dropped from second to fifteenth place in the number of students entering and completing postsecondary education compared to other countries (Palmer, Davis, Moore, \& Hilton, 2010). Similarly, Illinois is one of 24 states that have joined the Complete College America alliance, which calls for $60 \%$ of adults to have either a degree or postsecondary certificate by the year 2025. Reaching those goals calls for a significant and compounding annual increase in the number of awards produced each year (Complete College America, 2010; “How Far States Have to Go,” 2010).

Growth in educational attainment can be accomplished in one of two ways, greater participation from individuals who do not typically enroll in postsecondary education or improved retention and graduation rates for students already enrolled. In the 
case of individuals who do not typically pursue postsecondary education, a large number of these potential students belong to various high-risk student groups such as minorities, low income, first-generation, special needs, etc. In other words, these individuals are likely to need learning assistance outside the classroom (Schmid \& Abell, 2003), among other resources, if they are to remain enrolled and succeed in their coursework. They are also likely to need remediation (Lewis, 2004). Learning assistance centers have the potential to provide the support and services these students need if these students are to survive in a postsecondary setting. Similarly, learning assistance centers can play a role in boosting the retention and graduation rates for students who enroll as planned but then discover they are not prepared, academically (Wirt et al., 2000) or otherwise (Alexander \& Jetton, 2000; Hofer, Yu, \& Pintrich, 1999), for college. The structure of assessment in a learning assistance center may depend to some extent on the awareness of the staff regarding students' needs and student preparedness as well as how adequately the staff are prepared to deal with the needs and skill level of the students.

Student attrition is also associated with a loss of resources. State and federal funds that subsidize both students and institutions directly or indirectly are not being used efficiently when students drop out or flunk out of college. The Association for Institutional Research produced a study (Schneider, 2010) that sought to estimate the amount of money that is spent on students who do not return after the first year of college. Unfortunately, the limitations of the study were extensive. Based solely on the retention rate of full-time, first-time students at four-year institutions the author calculated a cost of \$321 million over a five year period in Illinois that was "wasted" on these students. This figure included amounts spent on student aid from both state and 
federal sources as well as state appropriations for operating expenses at the institutions. However, the author failed to account, or even attempt to account, for students who transferred or enrolled in a later term so the $\$ 321$ million figure is likely a great exaggeration. No data were included on students at community colleges or on part-time students, which are two populations known for high attrition rates (Dellow \& Romano, 2002). Although the methodology used to reach the $\$ 321$ million figure is certainly flawed, there is no doubt that the actual amount is substantial. Learning assistance centers have an opportunity to reduce the "waste" that is associated with student attrition by improving retention and college completion rates.

Table 1 provides a snapshot of the retention and graduation rate of first-time students at Illinois community colleges for the fall 2008 and fall 2006 cohorts of entering students respectively. These data are based strictly on first-time students who began in the respective fall-term, and the graduation rate data are for only those students who started as full-time. Retention is a measure of the number of students who return in the following fall-term, regardless of attendance in the intermediate spring and summer terms. Graduation rates are based on $150 \%$ of the normal time to degree which would be three years in this case. Graduation rate data for community colleges are often misleading due to the number of students who enroll with the intention of transferring before completing a degree. It can be seen, though, that the rate varies substantially between the institutions. This suggests that the lowest rates are not strictly due to the transfer nature of some students but instead due to some other variables. Furthermore, the retention statistics show that many students do not return for a second year of study at all of the institutions in this snapshot and even fewer students return if they began on a part-time 
basis. Therefore, although the data are not ideal, and some drop-off can be explained by transfer, it is clear that there is also room for improvement in the retention and graduation rates of these students. Learning assistance centers have the potential to provide the extra support and resources that these students need to remain enrolled but need to evaluate their effectiveness in meeting these needs.

Table 1

2013 Retention (Fall 2012 Cohort) and Three-Year Graduation (Fall 2010 Cohort) Rates

\begin{tabular}{|c|c|c|c|}
\hline \multirow[t]{2}{*}{ Community College } & \multicolumn{2}{|c|}{ First-time Student Retention } & \multirow{2}{*}{$\begin{array}{c}150 \% \text { Graduation } \\
\text { Rate } \\
\end{array}$} \\
\hline & Full-time & Part-time & \\
\hline Black Hawk College & $59 \%$ & $38 \%$ & $18.72 \%$ \\
\hline Carl Sandburg College & $51 \%$ & $30 \%$ & $25.70 \%$ \\
\hline CCC-Harold Washington College & $51 \%$ & $39 \%$ & $8.70 \%$ \\
\hline CCC-Harry S Truman College & $45 \%$ & $29 \%$ & $11.83 \%$ \\
\hline CCC-Kennedy-King College & $50 \%$ & $21 \%$ & $25.85 \%$ \\
\hline CCC-Malcolm X College & $38 \%$ & $30 \%$ & $8.43 \%$ \\
\hline CCC-Olive-Harvey College & $45 \%$ & $45 \%$ & $8.80 \%$ \\
\hline CCC-Richard J Daley College & $47 \%$ & $38 \%$ & $8.25 \%$ \\
\hline CCC-Wilbur Wright College & $57 \%$ & $41 \%$ & $13.86 \%$ \\
\hline College of DuPage & $68 \%$ & $53 \%$ & $15.85 \%$ \\
\hline College of Lake County & $65 \%$ & $42 \%$ & $16.75 \%$ \\
\hline Danville Area Community College & $56 \%$ & $37 \%$ & $28.74 \%$ \\
\hline Elgin Community College & $77 \%$ & $53 \%$ & $28.74 \%$ \\
\hline Frontier Community College & $76 \%$ & $44 \%$ & $57.14 \%$ \\
\hline Harper College & $68 \%$ & $45 \%$ & $24.12 \%$ \\
\hline Heartland Community College & $60 \%$ & $31 \%$ & $22.75 \%$ \\
\hline Highland Community College & $61 \%$ & $32 \%$ & $36.59 \%$ \\
\hline Illinois Central College & $61 \%$ & $32 \%$ & $23.22 \%$ \\
\hline Illinois Valley Community College & $63 \%$ & $47 \%$ & $30.09 \%$ \\
\hline John A Logan College & $59 \%$ & $34 \%$ & $25.63 \%$ \\
\hline John Wood Community College & $61 \%$ & $34 \%$ & $30.80 \%$ \\
\hline Joliet Junior College & $64 \%$ & $35 \%$ & $12.62 \%$ \\
\hline Kankakee Community College & $69 \%$ & $36 \%$ & $19.70 \%$ \\
\hline Kaskaskia College & $55 \%$ & $38 \%$ & $46.22 \%$ \\
\hline Kishwaukee College & $60 \%$ & $45 \%$ & $18.47 \%$ \\
\hline
\end{tabular}




\begin{tabular}{llcl} 
Lake Land College & $65 \%$ & $47 \%$ & $29.86 \%$ \\
Lewis and Clark Community College & $66 \%$ & $47 \%$ & $13.36 \%$ \\
Lincoln Land Community College & $60 \%$ & $47 \%$ & $25.34 \%$ \\
Lincoln Trail College & $65 \%$ & $15 \%$ & $43.48 \%$ \\
McHenry County College & $67 \%$ & $46 \%$ & $24.15 \%$ \\
Moraine Valley Community College & $68 \%$ & $41 \%$ & $20.48 \%$ \\
Morton College & $72 \%$ & $44 \%$ & $15.04 \%$ \\
Oakton Community College & $71 \%$ & $44 \%$ & $14.38 \%$ \\
Olney Central College & $69 \%$ & $32 \%$ & $37.10 \%$ \\
Parkland College & $54 \%$ & $36 \%$ & $16.26 \%$ \\
Prairie State College & $46 \%$ & $37 \%$ & $12.92 \%$ \\
Rend Lake College & $59 \%$ & $51 \%$ & $51.22 \%$ \\
Richland Community College & $65 \%$ & $29 \%$ & $21.11 \%$ \\
Rock Valley College & $66 \%$ & $46 \%$ & $22.07 \%$ \\
Sauk Valley Community College & $65 \%$ & $53 \%$ & $29.03 \%$ \\
Shawnee Community College & $52 \%$ & $52 \%$ & $28.04 \%$ \\
South Suburban College & $51 \%$ & $37 \%$ & $21.50 \%$ \\
Southeastern Illinois College & $60 \%$ & $25 \%$ & $23.93 \%$ \\
Southwestern Illinois College & $64 \%$ & $42 \%$ & $27.25 \%$ \\
Spoon River College & $59 \%$ & $48 \%$ & $22.09 \%$ \\
Triton College & $49 \%$ & $26 \%$ & $14.70 \%$ \\
Wabash Valley College & $62 \%$ & $7 \%$ & $44.44 \%$ \\
Waubonsee Community College & $68 \%$ & $42 \%$ & $30.15 \%$ \\
\hline Source: U.S. Deparm
\end{tabular}

Source: U.S. Department of Education, National Center for Education Statistics, IPEDS Data Center

\section{Postsecondary Educational Attainment and the Economy}

The need for increasing the numbers of adults with postsecondary training and credentials is not just about competing with other countries: it is about improving our own. Community colleges are not simply focused on credential completion but also on serving the needs of the local community and economy by providing skilled workers to meet local demand. Bureau of Labor Statistics projections indicate that jobs requiring at least some postsecondary certification or a degree will exhibit growth rates from 16 to 30 percent compared to growth rates of 8 to 11 percent for jobs requiring only on-the-job training (Holzer \& Lerman, 2007). Holzer and Lerman (2007) indicated that "roughly 
half of all employment today is still in the middle-skill occupations” (p. 3). Middle-skill occupations are those that require training beyond high school but less than a four-year degree (Stone, Blackman, \& Lewis, 2010). One example of such an occupation are health technicians who, as Holzer and Lerman (2007) noted, increased in number from 400,000 in 1986 to over 1 million presently. A 2003 report by the Aspen Institute (as cited in Holzer \& Lerman, 2007) found that adult workers with at least some college increased from 17 percent to 28 percent between 1980 and 2000, but projected that level to remain flat through 2020. "These projections suggest a serious slowdown in the growth of skills the top and the middle of the labor market (Holzer \& Lerman, 2007, p. 4).” Therefore, the number of middle-skill jobs is increasing at a faster pace than the population of adults with the skills needed to perform the tasks involved.

Increasing the number of skilled workers will also have an impact on the overall economy. The Organization for Economic Co-operation and Development (as cited in Holzer \& Lerman, 2007) projected that "each year of postsecondary education leads to an increased per capita output of between 4 and 7 percent.” A 10 percent increase in adults with more than a high school diploma but less than a four-year degree "would increase federal tax revenue by $\$ 14$ billion” while also saving the federal government “up to $\$ 2,500$ per person in reduced reliance on public assistance programs” (p. 20). Money invested in learning assistance has the potential for a positive return. What is not known is how learning assistance centers are measuring their performance in increasing student persistence and completion in light of this potential, and further, what is being done with the information. 


\section{Current Limitations in the Research of Learning Assistance Centers}

There are no large scale surveys or reports on learning assistance programs such as there are for student enrollments or institutional finances. Headcounts of students served by learning assistance centers may be tallied locally, but are typically not reported to external agencies. Similarly, the reporting of expenditures to the Integrated Postsecondary Education Data System (IPEDS) does not allow for an examination of the financing or staffing of learning assistance centers. Some institutions consider the support center to be an academic unit and report expenditures under instruction. Other institutions place such centers under student affairs and report expenditures under student services. In either case, the expenditures are combined with other multiple, unrelated units, making comparisons from one institution or sector to another institution or sector nearly impossible with IPEDS data. Staffing of learning assistance centers is even more difficult to compare since some institutions classify academic support center staff as professional staff, while others rely on undergraduate and graduate students to provide many of the services. The type and level of assessments being carried out or evaluation being performed will likely vary greatly based on the skill level of the staff employed and on the budgeting for the unit.

Therefore, in addition to the research questions noted earlier, the current study also surveyed community colleges on the size of the learning assistance center in terms of staff and budget, the qualifications of the staff, the types of services offered, the number and types of students served, and the organizational structure under which the center operates to provide context for the data collected on assessment and evaluation practices. For example, one might expect a center that is highly reliant on student peer tutoring to 
have minimal, if any, assessment measures since the financial investment in such a center is minimal while a center that employs a number of professional staff may be more concerned with measuring their effectiveness and using that data to guide improvement efforts since a larger financial investment has been made in the center. Finally, this study aims to promote greater attention to the role of learning assistance centers in postsecondary education and to open a dialogue about their potential for improving access, retention, and completion rates for all students.

\section{Methodology}

The author identified, via a web search, the administrators of learning assistance centers at 226 public two-year institutions with academic programs, including the associate's degree, that have an open admissions policy. A survey was sent to the administrators of the learning assistance centers at these community colleges and respondents were asked to record their level of agreement with a number of statements pertaining to program evaluation within their respective centers.

The first section of the survey collected information on the staffing, budget, structure, and services provided by the learning assistance center as well as their clientele. The second section contained a list of statements reflecting practices that, according to the literature, provide an effective foundation for program evaluation. The respondent was asked to rate each statement in terms of (a) the extent to which it "does reflect" actual practice in the evaluation of his or her learning center and (b) the extent to which it "should reflect" actual practice in the evaluation of his or her learning center. The data collected from this section attempt to show to what extent program evaluation is based upon those elements deemed essential in the literature on best practices in program 
evaluation and whether the respondents perceived that there was a mismatch between the actual practice and desired practice in the evaluations of their learning assistance centers.

The third section of the survey included a list of various measures that might, according to the literature, be used in the evaluation of a learning assistance center. For each measure in this section, the respondent was asked to (a) note his or her agreement that the measure does factor heavily in evaluations of his or her learning center and (b) note his or her agreement that the measure should factor heavily in the evaluation of his or her learning center.

Survey responses were analyzed based on the research questions this study seeks to address. A descriptive analysis of the structures and range of services offered by learning assistance centers was performed based on responses to part one of the survey. Survey responses were analyzed based on the research questions this study sought to address. A descriptive analysis of the structures and range of services offered by learning assistance centers was performed based on responses to part one of the survey. For each of the final two sections of the questionnaire, two analyses were conducted. First, descriptive data (mean and proportion of responses to each rating) were calculated and reported. Then, inferential statistics (t-tests) were used to compare (a) respondent perceptions of the extent to which the composite set of practices and measures was employed in the center's evaluation with (b) respondent perceptions of the extent to which the composite set of practices or measures should be employed.

This is an exploratory quantitative study based on a survey of a nationwide sample. Respondents may have felt compelled to answer questions on the survey based on how they would like to be perceived and not based on their actual practice. The 
author has attempted to minimize this behavior by assuring the participants that all responses would be anonymous. A qualitative component that included interviews of learning assistance center directors, students, faculty, and administrators would add value to this study, that is beyond the scope of the current study. Adding a qualitative component could be an additional study in the future and the findings of the present study would be useful in the design of such a qualitative piece. Finally, some variation in survey responses may have occurred due to confounding factors such as an external funding source that has certain evaluation and/or reporting requirements, different organizational and staffing structures, or variations in funding levels. The data collected in part one of the survey was designed to help address the impact of these variations on the data collected in parts two and three.

\section{Definitions}

Assessment in this study refers to the effort "to determine how well students are learning."...and is used to provide "feedback to students, educators, parents, policy makers, and the public about the effectiveness of educational services” (National Research Council, 2001, p. 1). Assessment in a learning assistance center refers to the effort to determine how well students learn either the study skills they must utilize to succeed in their academic course work or to learn specific content knowledge such as math or writing skills.

Program evaluation is the "application of systematic methods to address questions about program operation and results” (Newcomer, Hatry, \& Wholey, 2010, p. 5). Program evaluation in this study refers to the effort to measure the effectiveness of a learning assistance center. 
Learning assistance center is a "designated physical location on campus that provides an organized, multifaceted approach to offering comprehensive academic enhancement activities outside of the traditional classroom setting to the entire college community” (Arendale, 2007, p. 22). Services provided may include tutoring, study groups, support for special needs students, study skills instruction, writing or math skills instruction, computer assistance, and similar services.

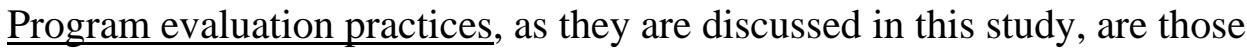
practices that several authors have identified in the literature as being crucial for the effective evaluation of a program. The author has grouped these practices into four themes as they are discussed in the literature review in the following chapter.

Program evaluation measures, as they are discussed in this study, are those measures that have been discussed in the literature as possible metrics for gauging the effectiveness of a learning assistance center. 


\section{CHAPTER II}

\section{REVIEW OF THE LITERATURE}

This study seeks to add to a small body of literature on assessment and evaluation within community college learning assistance centers via a survey of current administrators of those centers. This chapter will provide the reader with a review of the relevant literature that links the survey instrument described in the next chapter to the research questions outlined in the previous chapter. The literature review begins with an overview of learning assistance centers including what they do, how they are structured, and the role they play. It will then discuss the role of these centers on community college campuses and their work with the various student populations on those campuses. Next, the author will review the current state of assessment within learning assistance centers as it is reflected in the available literature regarding measures, the use of data, and the importance of assessment. The chapter concludes with a review of the literature on program evaluation. After defining program evaluation and discussing the intended outcomes of the program evaluation process, the author summarizes a series of "best practices” in program evaluation that have been identified in the literature and that serve as the guiding principles of the survey instrument design.

\section{Learning Assistance Centers}

The establishment of learning assistance centers at college campuses began in the early 1970s, the first at California State University - Long Beach (Arendale, 2010). Learning assistance centers can be found on many college campuses and have a multitude 
of names and arrangements under which they may function such as learning labs, learning centers, and student assistance centers. They may be housed under an academic division on a campus or under student services. The types of services they offer vary as well; including tutoring, study groups, support for special needs students, study skills instruction, writing assistance, math assistance, computer assistance, etc. Although such centers take on varied shapes and structures, a common theme that distinguishes a learning assistance center is its comprehensive nature and its mission within the institution (White \& Schnuth, 1990). Such centers do not serve only underprepared students: They serve the general student population as well and even the faculty at some institutions (Arendale, 2010).

\section{Challenges Faced by Learning Assistance Centers Within Community Colleges}

Learning assistance centers can be found within many four-year institutions, but are more prevalent and larger in scope when found in the community college system (Stern, 2001). This is not surprising since community colleges enroll greater numbers of under-prepared students. Arendale (2010) notes that one factor that lead to the growth of learning assistance centers was the lowering of admission standards. The expansion of “open-door” admissions at community colleges across the country was certainly a contributing factor in the development of these centers. Additionally, community colleges enroll greater numbers of students who display one or more demographic factors that have been linked to attrition (Schmid \& Abell, 2003), such as being employed while enrolling in coursework or having parental commitments, and who are therefore in greater need of support outside the classroom. Concerns about student retention were 
another factor Arendale (2010) noted as contributing to the growth of learning assistance centers.

There is certainly an intertwining of developmental education and learning assistance centers, especially at community colleges, so a discussion of one must include the other. Owing to the mission of the community college to serve the community, and because of “open-door" admissions policies, large numbers of "at-risk” students enroll. Risk factors include work and family obligations (Gilardi \& Guglielmetti, 2011), firstgeneration college enrollees (McCarron \& Inkelas, 2006), and a lack of readiness for college-level coursework due to deficiencies in reading, writing, and/or mathematics (Provasnik \& Planty, 2008). Although the mission of the learning assistance center may be to serve every student, the large number of developmental education students and the difficulties they face in moving through their academic courses and programs lead to a substantial amount of effort within the learning assistance centers to support these students.

Does developmental education cost the taxpayer twice, once in high school and yet again in college? Some feel that is the case, suggest Boylan and Saxon (2001). Whether one views developmental education as expensive or not depends more on one's philosophy regarding it than its true cost according to Boylan and Saxon. How much does developmental education cost? Various studies utilizing differing methodologies have suggested the cost at or below $\$ 1$ billion while higher education as a whole costs approximately $\$ 90$ billion. Boylan and Saxon warn however, "accounting techniques can lead cost estimates in any directions for which there is a politicized agenda” (p. 6). If learning assistance centers serve large numbers of developmental education students, 
then concerns regarding the funding that already goes to classroom instruction will only grow if additional funds are being expended for additional academic support outside of the classroom. Therefore it is important that learning assistance centers be able to document their value in assisting all students.

Another way to look at the issue is to consider the earning potential of prospective students. If only $30 \%$ of developmental students complete bachelor's degrees, then these students could generate nearly $\$ 90$ billion dollars of tax revenues in their lifetimes (Boylan \& Saxon, 2001). Similarly, the lack of appropriate skills has been estimated to cost businesses and schools $\$ 16$ billion per year due to the loss of productivity and need for remediation (National Education Summit on High Schools, 2005). Economic rewards are not limited to those who complete the bachelor's degree. The completion of an associate’s degree has also been shown to lead to greater earnings (Marcotte, Bailey, Borkoski, \& Kienzl, 2003). Learning assistance centers have the ability to assist both the students and the institution in achieving these outcomes.

Students in underrepresented populations such as certain minorities, those from low-income families, or those students requiring accommodations due to a disability are typically overrepresented in developmental coursework (McCabe, 2000; White, 2002) and it is the learning assistance center that provides the extra support and services these students need to help address the achievement gap (McCabe, 2000). Students who require remediation are less likely to persist and succeed in college, and as the amount of remediation required increases, the odds of obtaining a degree decrease (Weissman, Bulakowski, \& Jumisko, 1997). The practices of tracking and special education placement in the K-12 system may be causal factors in this trend. The practice of 
tracking leads to fewer opportunities and less challenging work for students placed in the lowest track, noted Oakes (1996). Additionally, higher numbers of minority students are placed in low track courses or are labeled as special education students and placed in restrictive or isolated environments. Enrollment patterns in developmental coursework at the college level seem to follow enrollment patterns in low-track classes in the K-12 system, with a disproportionately high number of minority students requiring such coursework when they enter college (Weissman, Bulakowski, \& Jumisko, 1998). Black students had the highest propensity for enrollment in developmental coursework in the 2007-2008 academic year with 45.1\% of first-year students enrolled followed by Hispanic students, $43.3 \%$ of whom enrolled in their first year (Aud et al., 2010). Only 31.3\% of white first-year students enrolled in that same year.

While proponents of tracking may argue that tracking is necessary for the good of those who require more remediation or that tracking provides additional opportunities for those who are ahead of their peers, Oakes (1996) has shown that such placements are often more aligned with race than they are with test scores. Additionally, low-track classrooms and schools in predominantly poor neighborhoods are often staffed by teachers who are less experienced or qualified than those found in advanced classes or more affluent neighborhoods (Skrla, Scheurich, Garcia \& Nolly, 2004). In such cases, the combination of open access and numerous developmental course offerings may be the only available path to success for significant numbers of minority students.

Race alone is certainly not the only influential factor. Twenty percent of all students in community colleges were from families whose incomes were under $\$ 25,000$ (Burd \& Field, 2004). Fifty-nine percent of the students had families who made $\$ 25,000$ 
to $\$ 74,999$, and the remaining $21 \%$ came from families that made more than $\$ 75,000$. These compare to percentages of 11, 48 , and 41 respectively for students at four-year institutions. Community colleges have twice as many “low-income” (under $\$ 25,000$ ) students as do four-year institutions, while four-year institutions have twice as many "high-income students" (more than $\$ 75,000$ ).

A lack of academic preparation on the part of students is not the only problem that colleges face. Institutions also have experienced a growth in the enrollment of students who are documented as having a disability, and therefore require accommodations (Thompson \& Bethea, 1996). Students with special needs are guaranteed rights through two important legislative acts, Section 504 of the Rehabilitation Act of 1973 (often simply referred to as Section 504), and the Americans with Disabilities Act of 1990 (ADA). Section 504 prohibits institutions that receive federal funding from denying students with disabilities an equal opportunity to benefit from all programs and services offered by the institution. Section 504 defines the rights of students with disabilities to participate in programs and the rights to have access to benefits and services at institutions that receive federal funding. Under Section 504, qualified individuals with disabilities are those who can perform the essential functions if provided with reasonable accommodations (Grossman, 2001).

While the scope of Section 504 is limited to institutions that receive federal funding, the Americans with Disabilities Act of 1990 (ADA) applies to all institutions (Ford \& Trotman, 2000). ADA also goes further than Section 504 by adding regulations for new construction and modifications for existing public facilities, regulations for access to telecommunications services, and accommodations are required not only for the 
individual attempting to participate but also any associated individuals. For example, if a student has a parent who is disabled, then the institution must make accommodations for the parent to participate in any campus activities regularly attended by parents. Under ADA, an individual is "disabled" if he or she meets any one of the following criteria, "has a physical or mental impairment that substantially limits a "major life activity," or has a record of such an impairment, or is regarded as having such an impairment (U.S. Department of Justice, 2004).” One other distinct difference between Section 504 and ADA: under Section 504, a student only has the right to file a complaint. Under ADA however, a student may sue the institution if he/she believes a violation of his/her civil rights has occurred.

The transition from K-12 education to higher education poses great challenges for special needs students as they move from a "centralized support system...that provides an IEP developed with input from multiple stakeholders” that is specific to the individual student's strengths and needs in the K-12 setting (Higbee, Katz, \& Schultz, 2010, p. 10). Once these same students enter higher education, they must become their own advocates and determine how to navigate the system to document their disability and seek the appropriate accommodations. This process, the authors noted, "can involve interactions with myriad offices and individuals, including separate conversations with each instructor every academic term (Higbee, Katz, \& Schultz, 2010, p. 10).”

Accommodations such as reading to special needs students; serving as notetakers; and transcribing students' tests, quizzes, and assignments are tasks that are commonly carried out by learning assistance centers on college campuses to fulfill the legal obligations of the institution. However, special needs students are sometimes 
reluctant to avail themselves of these services. Seeking out accommodations requires disclosure on the part of the student and such disclosure can carry negative consequences such as labeling or accusations of unfair treatment (Kalivoda, 2003).

Community colleges, as learning organizations, have been noted for their ability to respond to evolving societal demands (Closson, 1996), resulting in multiple missions such as developmental education, occupational training, or transfer/general education. Community colleges are typically more flexible than their four-year counterparts because of their community focus and because they are not so entrenched in tradition (Closson, 1996). Therefore, there exists the capacity in community colleges to benefit greatly from engaging in systemic and on-going assessment to respond to internal needs just as it has responded to external ones. Peterson and Einarson (2001) note that "a positive relationship exists between institutional uses and impacts of assessment and the comprehensiveness of an institution’s assessment approach” (p. 631).

\section{Assessment of Learning Assistance Centers}

It is clear that learning assistance has the potential to impact many varied groups of students who face difficult obstacles in achieving academic success. What is less clear is the extent to which institutions and learning assistance centers assess their effectiveness in helping students achieve success. When assessment is carried out, who is doing it and what are they measuring? What purpose does the assessment serve? What changes occur due to the assessment? After discussing the assessment movement in higher education, this section will then narrow the discussion to developmental education and learning assistance centers, distinct topics that do have some overlap due to the large population of developmental education students typically served in learning assistance 
centers. The section concludes with an overview of measures often used to evaluate learning assistance centers as found in the literature.

\section{The Assessment Movement}

The so called "assessment movement" can be traced back to several events in the early to mid 1980’s. Tennessee was the first state to institute a performance funding system for its higher education system (Astin, 1993). In the mid-1980's, a series of reports such as the National Institute of Education's Involvement in Learning, the Association of American College’s Integrity in the College Curriculum, and the National Governors Association's Time for Results focused the attention of both higher education and the public on the preparation of college graduates and the need for assessment (Palomba \& Banta, 1999). Such reports were following a trend in analyzing “outputs” of education found in the K-12 system after the publication of A Nation at Risk. Although several institutions answered the call, and a select few had already begun such assessment programs at this time, an executive order issued by William Bennett, Secretary of Education in 1988, requiring all federally approved accreditation organizations to include evidence of institutional outcomes in accreditation criteria meant that assessment would soon be a concern for all institutions (Palomba \& Banta, 1999). By 1995, 95\% of institutions had reported that they were engaged in assessment and 90\% had increased their activity level as compared to 1990 (Palomba \& Banta, 1999). In the late 1990’s there were 19 states that either already had implemented or were working towards implementing performance indicator systems that were tied to funding mechanisms (Burke, 1997). Themes found in present-day performance based funding include increased funding for course completion, degree completion, improved retention, and 
two-to-four-year transfer in states such as Indiana, Oklahoma, and Ohio (Midwestern Higher Education Compact, 2009). Tennessee’s model goes further by including a measure of the percentage of students in remedial coursework who then go on to complete college-level courses in the following year (Midwestern Higher Education Compact, 2009).

\section{The Lack of an Assessment Movement in Developmental \\ Education and Learning Assistance Centers}

Unfortunately, assessment of student learning in developmental education, and learning assistance centers specifically, has not garnered the same attention as assessment in college-level courses for several reasons. A national survey found that only $14 \%$ of developmental programs in two-year institutions are involved in on-going, systemic evaluation (Boylan, Bliss, \& Bonham, 1997). Developmental education has been referred to as the "elephant in the room" that no one wishes to acknowledge. It is sometimes considered only as a “necessary evil” (Boylan, Saxon, \& Link, 1999, p. 17 as cited in Chung, 2005), one that is often undervalued (Chung, 2005). Chung further posits that developmental education and learning assistance will continue in such a state because they lack an “overarching, shared theoretical framework” (p. 2) among professionals. If learning assistance centers are viewed as extensions of the developmental program then one might expect them to receive the same scant attention that developmental education has in the assessment schema of the institution.

Additionally, many practitioners fail to positively identify themselves as “developmental educators” (Chung, 2005, p. 10). Community college faculty in math and composition tend to consider themselves as instructors of their specialty who are also 
teaching developmental courses instead of identifying themselves as developmental educators, despite the fact that their teaching loads are often primarily composed of developmental courses. It is understandable then, why so few attend professional meetings or read journals devoted to developmental education (Chung, 2005).

The body of available literature is not without criticism as well. An exploratory analysis of 300 publication abstracts from assorted journals noted that on the rare occasion community college faculty publish research their focus is typically about the state of their individual institution and the papers typically discuss classroom-level studies (Safarik \& Getskow, 1997). Such efforts fail to provide either a policy framework or a national context. Similarly, although learning assistance centers employ a variety of strategies and methods to assist students, empirical studies in support of such techniques are few and typically done in a local setting within a narrow context (Hadwin \& Winne, 1996).

Engaging in outcomes assessment and evaluation that observes the changes in developmental students as they progress allows the opportunity for the organization, the students, faculty, staff, and administration, to learn. Learning, as defined by Argyris (1995), occurs "whenever errors are detected and corrected, or when a match between intentions and consequences is produced for the first time” (p. 20). To simply examine outputs such as course grades may (or may not) signify whether a particular student was successful, but they do not indicate what the program did to cause that success. In the case of failure, as evidenced by a high proportion of failing grades, how will the institution know what needs to be changed to produce better results? 
Assessment provides the opportunity to learn by forcing the institution to pay closer attention to how it responds to students and the effect those institutional responses have. Evaluation is necessary to determine if the assessment process is adequate or if the process could be improved. Tierney (2001) identified a lack of evaluative criteria as another common reason why reforms fail to take hold. When faculty or learning assistance staff take action such as teaching a lesson via one technique or another they do so with the intention of causing an impact on the student. This action sometimes leads to a positive consequence, student learning, but sometimes fails to make any impression on the student. Assessment allows the organization to determine if positive consequences are happening, and evaluation allows the organization to match intentions with those consequences, resulting not only in student learning, but also in institutional learning as well.

Assessment within the developmental classroom clearly presents significant challenges to the community college, but assessment of the assistance that is provided outside the classroom can be even more problematic. Although programs offering learning assistance have existed since the start of higher education in the United States (Maxwell, 1997), little attention has been made to evaluating such programs’ effectiveness (Simpson, 2002), and those that have often suffer from several limitations (Simpson, Hynd, Nist, \& Burrell, 1997).

\section{What to Measure?}

One of the significant outcomes of the early stages of the assessment movement was a shift in the unit of measure indicating effectiveness from statistics such as incoming students' GPA's and SAT scores (input measures) to outcome measures 
(Dellow \& Romano, 2002). As state governing bodies and regional accrediting agencies began to drive assessment, the outcome measures commonly valued were quantitative in nature such as graduation rates and retention rates (Burke \& Serban, 1998). Additional states, 36 of 50 in 2001, have made the connection between state funding and campus performance (Burke \& Minassians, 2001). This macro level view has resulted in a deemphasis on course or program-based assessment, which are the types of assessments faculty typically employ or are more amenable to employing.

It would seem that community colleges would have the most to gain by deemphasizing the input characteristics of students as a measure of quality since they enroll the majority of under-prepared students. However, the emphasis placed on graduation rates and/or retention rates is just as detrimental because it fails to acknowledge the multiple missions of the community college and the diverse demographics of incoming students. Tinto's (1993) model of student departure, characterizing attrition as a lack of fit between students and the requirements of college, predicts that students lacking academic preparation, enrolling part-time, and/or enrolling while working fulltime will display lower levels of involvement and, therefore, higher levels of attrition. Four-year models of attrition, when applied to community colleges, have typically accounted for only $8 \%$ to $25 \%$ of the total variance in attrition (Dellow \& Romano, 2002). However, when program completion is used as an indicator, either obtaining a degree or completing a core of job-related courses, community colleges exhibit completion rates comparable to four-year institutions (Dellow \& Romano, 2002).

States continue to overlook the significant differences between the mission of the community college and that of its four-year counterpart. In a study of twenty-nine state 
performance reports issued in 2000 and 2001, seven performance indicators were unique to community colleges, ninety-seven indicators were shared between community colleges and four-year institutions, and four-year institutions had twenty-nine unique indicators (Burke \& Minassians, 2004). Unfortunately, the study did not attempt to determine why community colleges had seven unique indicators while four-year institutions had twentynine. Perhaps it is because the role of the community college is under-appreciated and/or misunderstood?

An unfortunate side effect of the emphasis states put on data that is easily measured is that more difficult measures such as student learning, the primary focus of the community college, are often ignored (Zarkesh \& Beas, 2004). Perhaps it is somewhat remarkable then that community colleges have made progress in implementing assessment of learning outcomes in spite of the devaluation exhibited by the states in such endeavors. Bragg (1995) found that of fifty-four surveyed two-year institutions, 78\% were conducting outcomes assessment as part of an institution-wide effort. Although outcomes typically identified with the performance-based system were identified as being in use in this survey by several institutions (i.e. employment status and enrollment patterns), other outcomes included student and employer surveys, portfolios, capstone projects, tracking systems, and performance on various exams (standardized, licensure, certification, etc.).

A 1978 survey of approximately 160 institutions indicated that although many program directors replied that they were involved in evaluation of their programs, there were problems with experimental design, inadequate or inappropriate criteria, unwarranted generalizations, lack of attention to affective variables, and failure to 
determine long-term effects (Clymer, 1978). The use of GPA and attrition rates as indicators in such studies was common. Such efforts were criticized for failing to acknowledge that "evaluation... must be ongoing, formative, and cybernetic" (p. 2). Furthermore, directors of learning assistance programs should "determine the extent to which a program achieves its objectives, meets the needs of the students which it serves, effectively trains its instructors, and appropriately revises ineffective and inefficient components of the total program” (p. 2).

Yet, by 1997, little had changed. Program evaluations still relied heavily on comparisons between the GPA and retention rates of students who utilized program offerings compared to students who did not (Simpson, Hynd, Nist, \& Burrell, 1997). Unfortunately, such "control” groups often differ in preparation level from those students in the program. An additional concern is that when students' participation is via selfselection, this is usually an indication of a higher level of motivation (Simpson, Hynd, Nist, \& Burrell, 1997), an intervening variable often not controlled. In a study of supplemental instruction (SI), a particular form of learning assistance, those students who participated most frequently tended also to possess an internal locus of control (taking responsibility for one's actions instead of blaming others for outcomes) and greater levels of self-efficacy and self-esteem (Visor, Johnson, \& Cole, 1992). Simpson, Hynd, Nist, and Burrell (1997) note:

Many evaluations fail to control the interaction between and among variables, rely solely on pre-post gains, and fail to account for influences other than the learning assistance program when explaining gains.... [in addition] few studies adequately 
describe aspects of the students or instruction that would make results more meaningful, such as a student's strategic activities in regular coursework. (p. 66) Additional criticisms of learning assistance programs are that they focus on skills that do not, or are not, transferred to other courses or settings (Vincent, 1983) and that programs fail to address issues of transfer in assessment and evaluation schema (Simpson, 2002).

It is not surprising that learning assistance program directors would be admonished for failing to ground their assessment and evaluation efforts in current theory (Simpson, Hynd, Nist, \& Burrell, 1997) when others have posited that no such theory exists (Chung, 2005). Consider the role that learning assistance professionals serve in assisting students to develop appropriate study skills such as note-taking. A choice must be made between providing instruction in developing basic skills in a generic approach, taking notes in any setting, or in providing content-specific skills such as taking notes in a technical subject with specific and extensive terminology. The generic approach may provide an opportunity for the student to use the skills in multiple courses both in the present and in the future, but if the student does not see the utility in those skills in his/her present circumstance, then no improvement will occur. Unfortunately, the research in this area seems to be inconclusive in determining whether one approach is better than the other and instead suggests a mixed method that depends on the context, student and setting (Simpson, Hynd, Nist, \& Burrell, 1997).

Those involved in developmental education, and therefore concerned with assessment, must give some consideration to the fact that the goal of developmental preparation is to ready the student for college-level courses (Neuburger, 1999); learning outcomes should therefore be aligned with that mission. Classroom assessment 
techniques in developmental and college-level courses, typically include course examinations, submitted work such as homework, and course grades (Astin, 1993). Although a test score or semester grade in the developmental course may be some indication of whether a particular student was successful, it is the student's performance in subsequent coursework that will ultimately determine the level of success achieved.

Also worth noting are the linkages that have been found between success in the developmental classroom and success in the "traditional" outcomes of retention, graduation and GPA (Neuburger, 1999). The graduation rate of students enrolled in developmental courses at community colleges was $24 \%$ compared to $22 \%$ for those who didn’t enroll in developmental coursework in the early 1990's (Lewis \& Farris, 1996). Students who do participate in developmental education have also been found to earn higher grades and persist at greater rates (Boylan, 1985; Kulik \& Kulik, 1991). Additionally, developmental students who have access to comprehensive learning assistance outside the classroom make larger gains than those who do not (Kulik, Kulik, \& Shwalb, 1983; Starks, 1989). In fact, when one considers the change that takes place in a student between the time he/she first enrolls in a developmental course through the completion of subsequent college-level coursework, this achievement provides a valuable measure of the institution's impact on the student. As Astin (1993) notes when discussing his work experience in a medical setting;

Since some clients are in much worse shape than others when you first see them, you cannot judge the efficacy of your treatment simply in terms of the outcome, the condition of the patient at the termination of treatment; on the contrary, the effectiveness of treatment has to be judged in terms of how much improvement 
takes place... The output of an institution or program ... does not really tell us much about its educational impact or educational effectiveness in developing talent. Rather, outputs must always be evaluated in terms of inputs. (p. 16-17) Even if the student withdraws (officially or otherwise) in the subsequent course, follow-up is necessary to determine if the problem was of an academic nature or due to other issues in the student's life, as so often happens in the community college. Unfortunately, external pressures on higher education cannot be ignored and these pressures are growing. Public support of higher education in the form of taxes is either stagnant or has decreased in some states (Kelderman, 2011). How institutions view support services such as learning assistance centers will play a pivotal role in how increasingly limited funds are allocated within the institution. "Institutions improve student persistence through organized programs supported by adequate funding, administrative oversight, and favorable campus policies (Hossler, Ziskin, \& Gross, 2009, p. 2).” An effort has been made to attempt to relate expenditures on academic support to retention rates and graduation rates, and a positive correlation between such expenditures and success measures has been found (Gansemer-Topf \& Schuh, 2003). However, a limitation in such work is the reliance on the Integrated Postsecondary Data System (IPEDS) for the expenditure data. Academic support expenses included in the IPEDS report include "libraries, museums, galleries, audio-visual services, academic computing support, ancillary support, academic administration, personal development, and course and curriculum development” according to the IPEDS Glossary.

Therefore, it is difficult to measure the impact of "academic support" expenditures on retention or graduation rates when the label of academic support is so 
broad and includes many aspects outside of direct student interaction. However, further study on the impact of academic support expenditures on retention and graduation rate may lead to more finely tuned insights. Recent research has found that not only was there a relationship between academic support expenditures and student persistence and graduation, but also that the effect was greater at institutions with lower entrance test scores and institutions with higher need-based financial aid (Webber \& Ehrenberg, 2009). Students on need-based financial aid and students who scored poorly on college admissions tests are most likely to enroll at community colleges so academic support expenditures could be a variable with a measurable impact on student retention and graduation rates.

Graduation rates are often inappropriately used as the measuring stick of success in community colleges (Smith \& Vellani, 1999). Although some students enroll in a community college with the goal of obtaining an associate's degree or proceeding on towards a baccalaureate degree, others only intend to take courses that will upgrade vocational skills or fulfill personal interests (Walleri, Seybert, \& Cosgrove, 1992). In such cases, tracking students’ performance against their intended goals provides more meaningful feedback as to whether these students have achieved "success."

However, since degree attainment is one of the roles of the community college, and many outside the community college system value graduation rates as measures of success, it is certainly worth noting that students who enroll in developmental education are capable of succeeding. The National Study of College Remediation found that approximately half of 1,520 students enrolled in developmental education courses in 1990 were successful in both their developmental programs and in subsequent standard 
college level work (McCabe, 2000). On the other hand, as the need for remediation increases for a particular student (i.e. enrollment in multiple developmental courses) the student is less likely to succeed (Adelman, 1996). Students who enroll in developmental reading courses, in particular, are also less likely to complete a degree. Are institutions being fiscally responsible if they allow under-prepared students to enroll in any course they desire, granting them the "right to fail”? Most institutions have answered, “absolutely not.”

One important feature of learning assistance centers that fails to receive attention in the literature is the role that such centers play in providing a supportive environment for all students. It was previously noted that community colleges and developmental programs serve the needs of many students who have been previously disadvantaged or marginalized by providing students access through extensive developmental course offerings and support through student services such as learning assistance centers. Therefore, it is equally important that assessment and evaluation of the center's effectiveness in such a role be considered. “Creating an environment of assistance on campus is as crucial as providing assistance” notes Stern (2001, p. 4), "it is what encourages students to not only seek out services, but to feel as though they are receiving support from the campus as well.”

Unfortunately, as Astin (1993) notes, “environmental assessment presents by far the most difficult and complex challenge in the field of assessment. It is also the most neglected topic” (p. 81). While many have viewed high attrition rates as being due to student deficits, others have found that attrition rates are found to vary greatly from one institution to another even when the students share similar backgrounds (Bailey, Jacobs, 
Jenkins, \& Leinbach, 2003), indicating that institutional characteristics play a role in attrition as well.

Student services, and learning assistance centers specifically, may be the most important aspect of an institution's ability to retain minority and low income students and to assist them in persevering to their goals. It is through student services that the institution has the capability to establish a caring relationship for those students who are enrolled. When discussing institutional caring, Siddle Walker (1996) identified the following institutional traits: an awareness of student needs, an acceptance of the responsibility of the institution to meet those needs, and the implementation of structures that will allow the institution to meet those needs.

Assessment and evaluation must include oversight to ensure that the program is accomplishing these goals. In consideration of the diverse needs that accompany the growing diversity, in terms of ethnicity, age, and socioeconomic status, of community college students, the ability for programs to respond in nontraditional ways to meet their clients' needs should be considered as a benchmark for performance (Becherer \& Becherer, 1995). Additionally, a second benchmark should consider the extent to which programs create a sense of belonging for the students. Clearly, assessment and evaluation mechanisms for learning assistance programs must account for the programs' role in providing a safe and supportive environment for all students. Feedback from students in the form of surveys or interviews would provide the opportunity to collect data on a learning assistance center's efforts in this area. 


\section{Program Evaluation}

The discussion thus far has served to provide a contextual background for the operations and challenges of community college learning assistance centers and the current assessment environment. This study is focused on an exploration of program evaluation within these centers. The literature on program evaluation indicates the need for the following four requisites; alignment with mission/goals, involvement of stakeholders, the appropriate use of data, and adequate resources. These four requisites form the basis of the survey instrument used in this study.

\section{Alignment with Missions/Goals}

Program evaluation is the "application of systematic methods to address questions about program operation and results” (Newcomer, Hatry, \& Wholey, 2010, p. 5). Therefore, to undertake program evaluation within a center you must first be familiar with its operations and have some agreement as to what the desired results or outcomes are for those students served by the center. It is not surprising then that many (Berk \& Rossi, 1990; Newcomer, Hatry, \& Wholey, 2010; Yarbrough, Shulha, Hopson, \& Caruthers, 2011) consider an early step in the program evaluation process to be

discerning the goals of the program under evaluation. These goals may take the form of a mission statement but even if no such mission statement exists for the learning assistance center there needs to be agreement as to what the goals are before an evaluation plan can be put in to action.

The Joint Committee on Standards for Educational Evaluation (Yarbrough, Shulha, Hopson, \& Caruthers, 2011) goes further in their definition of program evaluation: 
- the systematic investigation of the quality of programs, projects, subprograms, subprojects, and/or any of their components or elements, together or singly

- for purposes of decision making, judgments, conclusions, findings, new knowledge, organizational development, and capacity building in response to the needs of identified stakeholders

- leading to improvement and/or accountability in the users' programs and systems

- ultimately contributing to organizational or social value.

The wording of the Joint Committee’s definition, “leading to improvement and/or accountability," is certainly interesting and worth further discussion as it relates to another term used in their definition: stakeholders. The evaluation of a program such as a learning assistance center could be for the purpose of improving the program for the students it serves or for the staff who carry out its functions, or it could be to satisfy the needs of an oversight agent such as the college administration, governing board, or an external funding agency. Are evaluators or staff performing the evaluation doing so to improve the quality of the program or are they doing so to determine if the program provides sufficient quality to continue to exist?

\section{Stakeholder Involvement}

The proper identification of stakeholders and their inclusion in the program evaluation process is one key to a successful evaluation plan. In its broadest sense stakeholders can include "individuals, groups, or organizations that can affect or are affected by an evaluation process or its findings” (Bryson \& Patton, 2010, p. 28). In the case of a learning assistance center the stakeholders could include students, staff that work within the center, faculty and other college staff, college administration, the 
governing body, an external oversight agency, an external funding agency, and even taxpayers. The level of engagement of these stakeholders will vary to some degree from one college to another, but there is likely a smaller subset of "key stakeholders" who are more engaged in the learning assistance centers work or interested in its improvement and/or results. Patton (2008) refers to an even smaller subset of this group known as the "primary intended users." These individuals are "selected to work with the evaluator throughout the evaluation to focus the evaluation, participate in making design and methods decisions, and interpret the results to assure that the evaluation is useful, meaningful, relevant, and credible” (p. 72). Whether the evaluation plan seeks to place an emphasis on the improvement of the program or to instead serve an accountability purpose for outside interests will depend on the makeup of this group of individuals. Program evaluation that serves purely an accountability purpose is "often not worth the cost of the evaluation” (Newcomer, Hatry, \& Wholey, 2010, p. 6) if it does not include program improvement as an intended outcome of the process. That is why the proper identification of the key intended users is vital.

When so many people from so many groups are involved in an enterprise, there can be several roadblocks. If assessment brings out ideas of standardized testing in one group, review of grades at the end of the semester in another group, and performancebased assessment in a third, then disagreement as to how assessment should be implemented is to be expected. Barriers to reform occur when individuals cannot agree on the problem to be addressed or approach the problem from different premises (Tierney, 2001). Another common obstacle to change is hesitancy by those who have seen other reform initiatives stall and fade away (Tierney, 2001). 
Those who attempt to begin, revitalize, or refocus assessment may face challenges eliciting buy-in and support from faculty who are hesitant, skeptical, or just set in their ways (Astin, 1993). Such individuals may employ a variety of defensive tactics (Astin, 1993) to prohibit change, tactics such as displacement or projection. The purpose of such games is to "obviate the need for serious consideration of the finding by undermining confidence in the assessment” (p. 136). Critics of assessment in developmental education could argue that the under-preparedness of the developmental students undermines the ability to effectively assess them. However, such criticisms fail to acknowledge Astin’s (1993) call to assess the growth that takes place with regards to the incoming state of the student. The goal of such critics is to save face (Argyris, 1995) by attributing the cause for any deficits found in the assessment process or data to the preparation level of the students.

The need for faculty, or staff in the case of a learning assistance program, to take ownership in assessment and evaluation design and implementation is a recurring theme in the literature (Astin, 1993; Banta, Lund, Black, \& Oblander, 1996). Administrative support is crucial in beginning such endeavors and sustaining them. It is the role of the administration to create an enabling environment to support and encourage faculty to begin assessment (Hadden \& Davies, 2002) and to move faculty beyond awareness and towards responsibility. A critical component to sustaining assessment is moving assessment from mere innovation to institutionalization (Gray, 1997). If, as the literature strongly suggests, faculty ownership of assessment is so vital to successful assessment and evaluation initiatives, then an important task of the administration is to grow informal leadership (Roueche, Roueche, \& Ely, 2001). As Taber (as cited in Roueche, Roueche, 
\& Ely, 2001) suggests, formal leadership is responsible for supplying the energy, commitment, and foresight necessary to develop momentum, but the job of informal leaders is to sustain it.

First, administrators must determine and address potential barriers among the faculty or program staff. Common objections include the fear of assessment as a form of individual faculty or staff evaluation (Terenzini, 1989), a perception that assessment is a control mechanism for campus leaders (Kirkland, 1997), the belief that assessment only serves an accountability purpose for external groups (Hadden \& Davies, 2002), and the fear that assessment takes away precious time better spent on instruction. There are several characteristics that leaders must possess and/or develop to address these concerns before successful assessment and evaluation programs can be implemented, the most important of which may be trust. Trust is needed to demonstrate "that the purpose of assessment is to improve teaching and learning rather than to harm any individual student, faculty member, or program” (Hadden \& Davies, 2002, p. 256).

Administrators must also be aware of the various political forces within or across programs and departments and maneuver appropriately to help establish and sustain assessment initiatives (Seagren, 1993). A disconnect commonly exists between academic affairs and student affairs in most institutions, leading to the fragmentation of responsibility for student outcomes with the primary responsibility resting in the academic side (Ewell, 1985). In the case of developmental education students in the community college setting however, student affairs personnel are vital to student success. If informal leaders of the assessment movement on campus do not recognize or address this possible chasm, then formal leadership may be required. 
Special attention to the thoughts and practices of middle-level student affairs administrators may be required in developing assessment and evaluation schema for learning assistance programs. A survey of 276 such persons in the state of Texas (Fey \& Carpenter, 1996) found that student affairs administrators did not view evaluation as important and did not believe professional development was needed in that area. Such views may be crippling to assessment and evaluation initiatives in learning assistance programs. If culture is defined according to what leaders pay attention to, staff will quickly learn that assessment and evaluation is not important. Campus leaders who spend time on symbolic activities that aim to position student learning as a primary value, suggests Favero (2002), will increase participation levels of faculty and staff and improve social integration.

Last but not least, the role of the student must also be considered when discussing the stakeholders involved in the evaluation of learning assistance centers. Communication with the students about the purposes of assessment and how it will be used to assist the students must take place so that students know they are valued and respected. Assessment activities should be embedded within the course or within the activity in a learning assistance center so that the assessment reflects an authentic and ongoing view of the students' performance, as opposed to external assessment initiatives that have no relevance for the student and therefore lack students' full engagement or motivation (National Research Council, 2001).

One reason that program evaluation carried out for only accountability purposes, as alluded to earlier, is to be avoided is that it can lead to goal displacement. If program staff are asked to address measures that are inappropriate or not aligned with the goals of 
the center than the staff will "perform toward the measures but sacrifice the real program or organizational goals in the process” (Poister, 2010, p. 108). One example would be the use of the number of students served as a performance indicator. Center staff may rush through work sessions with students to increase the number that could be served without truly addressing the needs of the students seeking assistance. Among the many challenges to the use of evaluation and performance data the following highlight the problems that an accountability emphasis can cause or exaggerate with the program staff;

- a compliance mentality among staff regarding collection and reporting of program data and a corresponding disinterest in data use

- resistance to adding the burden of data collection to staff workloads

- lack of compelling examples of how evaluation findings or data have been used to make significant improvements in programs (Newcomer, Hatry, \& Wholey, 2010, p. 26).

Staff need to know that the time and effort they spend on program evaluation will lead to program improvements if those staff are to fully engage in the work of collecting the relevant data and show interest in its use. The American Evaluation Association (2004) ratified Guiding Principles for Evaluators in 2004 that addressed the issue of the burden for those staff who contribute versus their ability to benefit from the exercise when they stated that "evaluators should seek to ensure that those who bear the burdens of contributing data and incurring any risks do so willingly, and that they have full knowledge of and opportunity to obtain any benefits of the evaluation.” 


\section{Appropriate Data Use}

After determining the scope and role of stakeholders and who is a key intended user, as well as reaching agreement as to the desired results of the program, the next task is to determine what measures will be used to track progress or determine the success in accomplishing those results. There are a variety of performance measures one might use in a program evaluation; outcomes, cost effectiveness, outputs, efficiency, service quality, and customer satisfaction (Poister, 2010). In the case of a learning assistance center we might consider outcomes such as grades, retention rates, graduation rates and customer satisfaction (which might include surveys of the students who receive services or the faculty of those students). Although a measure like the number of students served might result in goal displacement as discussed earlier it would still be useful to know if there are times during the day or week when the center is under-staffed or over-staffed for the demand. Newcomer, Hatry, and Wholey (2010, p. 13) offer some guidance in choosing measures by asking evaluators to consider answering questions such as;

- $\quad$ Are the measures relevant to the activity, process, or behavior being assessed?

- What measures have other experts and evaluators in the field used?

- What do program staff, customers, and other stakeholders believe is important to measure?

The Joint Committee on Standards for Educational Evaluation's definition of program evaluation stated, among other things, that program evaluation leads to improvement in a program (Yarbrough, Shulha, Hopson, \& Caruthers, 2011). This improvement doesn't come about simply by reviewing the results of a program evaluation exercise, but instead it is the result of changes implemented in the program 
based on the results of the program evaluation. This is another issue that requires the attention of the proper stakeholders as some changes may require the approval or involvement of college administration or a governing body and they may require additional funds or changes in how funds are used. One condition of a successful evaluation process is that intended users are "willing and able to use evaluation information” (Wholey, 2010, p. 83). If stakeholders with sufficient “power” aren’t engaged in the process or are not willing to follow through on actions suggested by the evaluation data then improvement in the program will not take place.

\section{Adequate Resources}

Faculty committed to engaging in assessment need more than training and encouragement. They also need resources. Administrators who fail to provide resources for assessment and evaluation will cast doubt on how highly such endeavors are valued and will limit the institution's ability both to carry out the initiative and to benefit from it. Release time and other mechanisms such as professional development funds that allow staff to attend conferences and workshops are important as faculty and staff need time to discuss and plan any new initiative (Hadden \& Davies, 2002). Faculty and staff will

likely need technical assistance from institutional researchers in gathering and analyzing data. Unfortunately, community colleges have failed to expand institutional research capacity despite the increasing demands of assessment and evaluation (Cohen \& Brawer, 1996). Through assessment and subsequent evaluation, suggested changes to practices, policies, and structures may result. Administrators must not only be open to the discussion of such changes, but also willing to work with faculty and staff to identify and secure the resources necessary to make such changes. 
Administrators who demonstrate they are supportive, figuratively and financially, of enacting change based on assessment and evaluation findings will reap proportionate rewards. Astin and Ewell (as cited in Peterson \& Einarson, 2001) have identified a positive relationship between institutional usage and impacts of assessment to the comprehensiveness of the institution's approach. If faculty believe that assessment will serve a purpose (i.e. result in change), then they are more likely to engage in the practice. However, the purpose must be internally beneficial to the institution, as opposed to serving an accountability purpose to outside groups, to elicit the greatest amount of participation (Peterson \& Einarson, 2001).

\section{Summary}

In summary we can identify four dimensions of what we can refer to as "best practices” in program evaluation. First, the evaluation must be aligned with the mission and/or goals of the program. This requires the program to have a mission or goals and that those involved with the program are in agreement and understand what that mission is for the program or what goals the program is trying to achieve. Second, those individuals that are involved with the program or who are to be impacted by the program, the stakeholders, need to be involved in the design and implementation of the program evaluation. Soliciting their involvement in the design and implementation will demonstrate that their opinions are valued and will create "buy-in" to the evaluation process. The stakeholders will likely show a greater willingness to participate and will be more open to the resulting discussion when data have been collected or decisions are to be made based on the evaluation process and the data that was collected. 
Third, the data that is collected through the evaluation process must be useful for decision-making and this decision-making must lead to improvement. Stakeholders will expend some effort in the process of collecting data so they must know it is a worthwhile endeavor and that the effort will lead to improvement as opposed to serving purely an accountability function, otherwise the stakeholders will disengage from the process. Finally, there must be the capacity to perform program evaluation. Time and resources are needed to establish a mission and/or goals if they do not already exist. The design of an evaluation process and the collection of data will take additional time and may require additional resources such as the assistance of staff trained in program evaluation or in data systems to manage the information. Implementing changes that are recommended via the program evaluation process may require additional resources as well. These four dimensions were the basis for this study's questionnaire discussed in the next chapter. 


\section{CHAPTER III}

\section{METHODOLOGY}

This was an exploratory study of program evaluation in learning assistance centers in community colleges designed to address the following research questions;

1. How prevalent is the practice of program evaluation in community college learning assistance centers? That is, what proportion of learning assistance centers have conducted an evaluation of their services in the past two years?

2. What practices and evaluation measures do community college learning assistance directors perceive they should be using in the evaluation of their program and what practices and evaluation measures are actually being used?

Is there a gap between the directors' perceptions of what practices and evaluation measures they are using and what practices and evaluation measures they should be using?

These questions were answered through a national survey of learning assistance center directors collected through two different samples. First, a sample of community colleges that enroll between 10,000 and 20,000 unduplicated students over the 12 month year was used. However, the response rate was insufficient so a second sample was added that was not restricted by enrollment size.

This study did not seek to evaluate success of outcomes for learning assistance centers, only to examine the current state of program evaluation as it existed in the centers included in the combined sample. This chapter will describe the method of the 
sample selection for the survey, the construction of the survey instrument and how the survey items related to the discussion of the literature in the previous chapter, the analysis of the data collected through the survey, and limitations of the current study.

\section{Sample Selection}

Initially, random sampling was not used in this study since learning assistance centers are not found on all community college campuses. As the enrollment of an institution grows, it is reasonable to assume that the number of students needing the services provided by a learning assistance center increases as well, thereby increasing the likelihood of finding such a center on the campus. Therefore, the following criterion was first used to identify a community college as a potential member of the sample: The institution had to be classified as a public two-year institution with an open-admission policy that granted degrees and offered academic programs as defined by the Integrated Postsecondary Education Data System (IPEDS), which was the source from which the institutions were identified. Because this criterion produced a large list of potential institutions for the sample, 920, an additional criterion regarding the enrollment of the institution was employed to make the study more manageable. Restricting the 12-month unduplicated enrollment, also from IPEDS, to a range of 10,000 to 20,000 students reduced the potential sample to 223 institutions.

The following process was used to select the community colleges in the nationwide sample. The "download custom data files" option of the IPEDS Data Center was the starting point. The "EZ Group" option was used in the institution selection screen with the following parameters, identified in Table 2, checked for the 2011 collection year: 
Table 2

IPEDS EZ Group Parameters Used to Identify Sample

\begin{tabular}{ll}
\hline IPEDS EZ Grouping Category & \multicolumn{1}{c}{ Selected Category } \\
\hline Sector & Public, 2-year \\
Degree-granting status & Degree-granting \\
Institutional category & $\begin{array}{l}\text { Degree-granting, associate's } \\
\text { and certificates }\end{array}$ \\
Highest degree offered & Associate's degree \\
\hline
\end{tabular}

Applying these criteria yielded 980 institutions before entering the variable selection process. Next, criteria detailed in Table 3 (below) were selected from the corresponding IPEDS surveys:

Table 3

Surveys and Variables Used to Identify Sample

\begin{tabular}{ll}
\hline \multicolumn{2}{c}{ Institutional Characteristics Survey } \\
IPEDS Survey and Variable Category & Selected Variable \\
\hline & \\
Types of educational offerings & Academic \\
Admission considerations & Open admission policy \\
& \\
\hline Enrollments - 12-month unduplicated headcount enrollment: 2010 - 2011 \\
IPEDS Survey and Variable Category & Selected Variable \\
\hline & \\
Level of student & Undergraduate \\
12-month enrollment & Grand total \\
\hline
\end{tabular}

The IPEDS data center produced two comma-separated value files with the requested data; the institutional characteristics survey data were in one file and the enrollment survey data were in the other. These two data sets were then combined into 
one with schools matched by their UNITID number. Next, the data were sorted by "open admission policy,” and 30 institutions were removed from the sample because they indicated "no,” and one institution was removed because it responded "not applicable.” Out of the original 980 institutions, this reduced the potential sample to 949. The remaining institutions were then sorted by whether they offered "academic" programs, and another 29 institutions were removed because IPEDS indicated the response was an “implied no.” Finally the remaining 920 institutions were sorted by the 12-month headcount enrollment. When the list was filtered to only include institutions with a 12month unduplicated enrollment between 10,000 and 20,000, 223 institutions were identified as the potential sample.

The author then visited the website of each of those institutions to determine if a learning assistance center was present; that is, a unit within the college that contained some combination of student support services of an academic nature was present; examples included tutoring, math or composition assistance, instruction in study habits, or services for students with special needs (e.g., services provided under Section 504 or ADA), or similar types of services. If the college had such a center, then that institution remained in the sample for the survey. First the author followed any links on the institution's homepage that referred to "student services” to see if a center was identified, but if no center was listed, a search term was entered in the institution's homepage search engine to determine if a center was present. The following terms and phrases were used on each site’s search engine: learning assistance, study skills, tutoring, special needs, writing lab, student services, and student support. The author did not select a center that only specialized in one type of support such as a math center or a writing lab. The center 
had to offer a broad enough set of services that all enrolled students could be assisted in one or more areas such as math skills, writing skills, content tutoring, or study skills.

Out of the potential sample of 223 institutions there were 109 institutions that met these criteria and were included in the initial sample population for the survey. During the web search the author recorded the name of the administrator of each learning assistance center so that a letter could be sent to his or her personal attention. This letter was a request for the center director to participate in the study by completing a survey online through the "Survey Monkey" service. The letter provided the directors with the web address and instructions necessary to complete the survey. A reminder email was sent approximately two weeks after the letter was received. A second email reminder was sent one week after the first. Both the letter and the survey itself informed the directors that their responses would remain anonymous. The survey (as noted below) included three sections: (a) contextual information about the respondent's learning assistance center, (b) conditions for program evaluation, and (c) evaluation measures.

However, the response rate of this initial group was insufficient; 25 responded, but only 15 respondents completed the second and third sections of the survey (described below), so the sample was then expanded by removing the enrollment restriction to revert back to an initial group of 920 institutions. Removing the 223 institutions already considered reduced this group to 697 institutions. This list of institutions, as downloaded from the IPEDS Data Center, was listed by order of their Unit ID, a number assigned by the Office of Postsecondary Education when an institution first participates in IPEDS, and every fourth institution, $25 \%$ of the population, was then selected for possible inclusion in the final sample. The websites for these 174 institutions were then reviewed, 
just as they were for the first sample selection, and centers were found at 117 of these institutions, increasing the size of the total sample surveyed to 226 learning assistance directors. The learning center directors at these 117 additional colleges were contacted; 36 responded, and of those who responded, 28 filled out the second and third sections of the questionnaire.

This sample of 226 institutions represents approximately $23.8 \%$ of the total number of public two-year academic degree-granting institutions with an openadmissions policy. This small sample size poses limitations on attempts to generalize the findings to all such institutions. However, learning assistance centers were only found at half of the larger enrollment institutions identified in the sample selection process so the sample size likely represents a larger percentage of institutions that have a learning assistance center, as defined in Chapter I, as compared to the total number of institutions including those that do not have a learning assistance center.

\section{Design of the Survey Instrument}

The survey instrument (Appendix A) consisted of three parts. Part I was designed to provide descriptive information about the respondent's learning assistance center in terms of structure, staffing, budget, services provided, and the number and types of students served. The data collected in Part I was meant to provide context for the responses in the following sections, but the response rate was too low to make connections between contextual factors and the responses to Parts Two and Three of the survey.

The remaining two sections of the survey applied to those learning assistance centers that had undergone an evaluation in the last two years. Therefore the respondent 
must have indicated that their program had conducted an evaluation in the last two years to proceed. Part II of the survey presented the learning assistance center administrators with 21 statements regarding "best practices" in program evaluation based on the discussion in the literature review found in the previous chapter. First, the administrators were asked to rank their level of agreement as to whether each of these statements $\underline{\text { does }}$ reflect actual program evaluation practice in their center. Next, the administrators were asked to rank their level of agreement as to whether each statement should reflect the actual practice of evaluation in their center. Items one and two addressed the issue of a program's mission or goals, items three through 12 examined the issue of stakeholder involvement, items 13 through 17 are concerned with the use of data in the evaluation process, and the final set of items gauge the center administrators' views on the capacity of their program to effectively carry out evaluation.

The design of Part III is similar to Part II, however here the learning assistance center administrators were asked to rank the use of various measures found in the literature that one might use to evaluate a learning assistance center. First, the center administrators were asked to rank their level of agreement as to whether each measure did factor heavily in the evaluation of their center. Next, the center administrators ranked their level of agreement as to whether each measure should have factored heavily in the evaluation of their learning assistance center. Therefore, not only did this survey address the question of what measures are currently being used in the evaluation of learning assistance centers, but it was also designed to indicate if there was some controversy around some measures; that is, if perceptions of practices and measures actually used in evaluation differed from perceptions of what practices and measures should be used. 
The author solicited the National College Learning Center Association (NCLCA) for assistance in assembling a group of learning center administrators to pre-test the survey instrument to determine if the respondents interpreted the questions and answer choices in the way that the author intended. This group of four volunteers was provided access to the survey website where they completed the survey, and subsequently discussed any concerns they had regarding the survey items via email with the author. Some minor wording changes were made to further clarify a few items and some additional response choices were added to the item regarding the types of services that were offered in the center. No major concerns were identified in the pre-test. The final version of the survey was then administered to the nationwide sample of community college learning assistance center directors as discussed previously.

\section{Analysis of the Survey Responses}

Survey responses were analyzed based on the research questions this study sought to address. A descriptive analysis of the structures and range of services offered by learning assistance centers was performed based on responses to part one of the survey. For each of the final two sections of the questionnaire, two analyses were conducted. First, descriptive data (mean and proportion of responses to each rating) were calculated and reported. Then, inferential statistics (t-tests) were used to compare respondent perceptions of the extent to which the composite set of practices and measures was employed in the center's evaluation, with respondent perceptions of the extent to which the composite set of practices or measures should be employed. 


\section{Limitations of the Present Study}

This was an exploratory quantitative study based on a survey of the directors of learning assistance centers at a small nationwide sample of community colleges. Respondents may have felt compelled to answer questions on the survey based on how they would like to be perceived and not based on their actual practice. The author attempted to minimize this behavior by assuring the participants that all responses would be anonymous. A qualitative component that included interviews of learning assistance center directors, students, faculty, and administrators would have added value to this study but such a component was beyond the scope of the current study. Adding a qualitative component could be an additional study in the future and the findings of the present study would be useful in the design of such a qualitative piece. 


\section{CHAPTER IV}

\section{RESULTS}

The total sample that was contacted by letter initially and then via reminder emails consisted of 226 learning assistance centers. The response rate was 27\%, 61 of the 226 directors who were contacted. This chapter will discuss the results of the survey responses to each of the three sections starting with the contextual information in section one. Next, descriptive statistical summaries of the responses to section two of the survey regarding program evaluation practice will be discussed as well as a comparison, via t test, between the group means for responses to the "does reflect" and "should reflect" composites. A similar analysis, descriptive statistical summaries and comparison via $\mathrm{t}$ test, of the responses to the "actual use" and "should use" responses to the potential evaluation measures will conclude the chapter.

\section{Section One - Contextual Information}

The introduction to learning assistance centers in Chapter I indicated that they could be found in either the academic affairs division or the student affairs division of an institution. The responses supported this statement, as 33 directors indicated alignment with the academic affairs division and 18 reported an alignment with the student affairs division. One director responded that the center fell under both divisions. There were nine additional responses that indicated the center was aligned with some other division, such as the library, but it was not clear if these "other” divisions may in fact be aligned with either the student affairs or academic affairs division at these institutions. 


\section{Staffing}

Responses to the staffing-level items indicate that part-time employees and students are often utilized heavily to deliver assistance and educational services in learning assistance centers. Table 4 provides the descriptive statistical summaries of the responses to the staffing questions. The average number of part-time employees is nearly three times larger than the average number of full-time employees. The average number of student employees is nearly six times larger than the average number of full-time employees. Respondents were instructed to only count student employees who delivered services such as tutoring. Student employees whose primary function was to provide clerical/secretarial support were to be counted in the clerical/secretarial counts. The student employee count had the largest range and variance of all the staffing items indicating that their use varied greatly from one center to another.

Table 4

Staffing Levels in Respondents’ Learning Assistance Centers

\begin{tabular}{lrrrrr}
\hline Staff Category & Mean & Median & Mode & Min & Max \\
\hline Full-Time & & & & & \\
Administration/Managerial & 1.26 & 1 & 1 & 0 & 7 \\
Faculty & 0.87 & 0 & 0 & 0 & 20 \\
Professional staff & 1.93 & 1 & 0 & 0 & 12 \\
Clerical/Secretarial & 0.79 & 0 & 0 & 0 & 5 \\
Total Full-Time & 4.85 & 3 & 1 & 0 & 33 \\
Part-Time & & & & & \\
Administration/Managerial & 0.28 & 0 & 0 & 0 & 3 \\
Faculty & 5.51 & 0 & 0 & 0 & 130 \\
Professional staff & 6.74 & 2 & 0 & 0 & 45 \\
Clerical/Secretarial & 1.61 & 0 & 0 & 0 & 20 \\
Total Part-Time & 14.13 & 8 & 0 & 0 & 130 \\
Students & 29.38 & 20 & 0 & 0 & 120 \\
& & & & & \\
Total Staff & 18.98 & 11 & 5 & 1 & 148 \\
Total Staff and & 48.36 & 34 & 11 & 5 & 235 \\
Student Employees & & & &
\end{tabular}


Administrative/managerial headcounts were small with typically one full-time headcount and no part-time staff in administrative/managerial roles. Full-time staff classified as professional were also minimally reported with a mean of 1.93, median of one, and mode of zero. Part-time professional staff were reported in greater numbers in many cases, mean of 6.74 and median of two, but the summary statistics in Table 4 indicate some variance in these responses, particularly a mode of zero and range of 45 .

Faculty participation in the delivery of services is minimal but does exist. The mean number of full-time faculty employed was less than one (0.87) but the median and mode were both zero since only 14 of the 61 respondents reported having full-time faculty. The summary statistics (including maximum and minimum) provided in Table 4 show that the mean for this item has been inflated due to some outliers. This is also the case for the use of part-time faculty where a mean of 5.51 is accompanied by a mode and median of zero where outliers have again inflated the mean.

In the author's experience, the role of clerical/secretarial staff is important in the program evaluation effort, because those staff schedule the appointments for students to meet with staff and tutors, record and enter student usage data, and produce the student usage data that are included in reports on the activities of the learning assistance center. Therefore, it is unfortunate that the mean numbers of both full-time and part-time clerical/secretarial staff were so low, 0.79 and 1.61 respectively. The medians and modes were even lower, both zero for full-time and part-time. A potential question for future exploration would be whether learning assistance center directors felt they had an adequate level of clerical/secretarial staff to support program evaluation efforts. 
The mean, median, and mode all indicate that student employees provide assistance and educational services in many learning assistance centers, 56 of 61, and often outnumber other categories of staff in this sample. The involvement of students in the practice of program evaluation, explored in section two of the survey, takes on even more importance when one considers that students represent two separate groups of stakeholders; one group of students consists of the clients who receive services, and another group of students represent staff who are responsible for delivering those services and whose effectiveness in fulfilling their roles needs to be monitored. Each group of students can both contribute and benefit from involvement in the program evaluation process.

\section{Funding}

The majority of the learning assistance centers, 57 of 61, indicated that they were funded by the institution as part of the regular operating budget, and one did not respond. Two of the three that were not funded by the institution responded that the center was supported by grant funds. One center reported that student fees, collected of all students regardless of usage, provided the only revenue source for the center. Twenty-six of the centers funded by the institution were also supported by grant funds as well, while two that received grant funds did not receive institutional support. Student fees, collected from all students regardless of usage, provided supplemental funding for 10 centers. One center reported that revenue was also generated by providing test proctoring services to outside parties, and another center was supported by the school's foundation but both also received institutional operating funds and grant support. 
The survey attempted to collect information about the operating budgets of these learning assistance centers in an attempt to provide additional context for the responses to other questions and to inform the field about the typical budgets for such centers. However, it appears that the question may have not been clear, as some of the responses do not appear to be valid. For example, one center that reported employing three fulltime staff and three part-time staff also reported that their annual budget was $\$ 9,347$. Perhaps some interpreted the question as referring to expenses exclusive of personnel costs (salaries and benefits), such as supplies or professional development, while others who reported yearly budgets of $\$ 500,000$ to $\$ 1,132,000$ included personnel costs. Although the survey was pre-tested, the pre-test group did not suggest any changes or indicate any confusion with this item.

\section{Learning Assistance Center Services}

Math assistance/tutoring was the only service that all 61 of the centers reported offering. This is not surprising considering the large numbers of students enrolled in community colleges who require remedial/developmental coursework in mathematics (Parsad, Lewis, \& Greene, 2003). Assistance in writing, reading, and computer skills were also very popular. Some centers, 13 of 61, were engaged in academic advising activities in addition to providing learning assistance services. Table 5 summarizes the prevalence of the various services offered. In terms of the number of services offered within a given center, the mean was 10 and the mode was 11 , which would indicate that these centers typically offer a number of various services to support students in multiple ways. 
Table 5

Prevalence of Services Offered in Learning Assistance Centers

\begin{tabular}{lcc}
\hline \multicolumn{1}{c}{ Service Provided in Learning Assistance Center } & $\begin{array}{c}\text { Number of } \\
\text { Centers }\end{array}$ & $\begin{array}{c}\text { Percentage of } \\
\text { Centers Offering } \\
\text { Service }\end{array}$ \\
\hline Math assistance/tutoring & 61 & $100.0 \%$ \\
Writing assistance/tutoring & 53 & $86.9 \%$ \\
Reading assistance/tutoring & 53 & $86.9 \%$ \\
Computer skills assistance/tutoring & 52 & $85.2 \%$ \\
Subject matter other than math, reading, writing, or computers & 58 & $95.1 \%$ \\
Study skills assistance & 52 & $85.2 \%$ \\
Services for special needs students & 34 & $55.7 \%$ \\
Assistance for developmental/remedial education courses & 44 & $72.1 \%$ \\
Study groups & 39 & $63.9 \%$ \\
Peer tutoring & 54 & $88.5 \%$ \\
Classroom presentations & 36 & $59.0 \%$ \\
Programs for students on academic probation & 15 & $24.6 \%$ \\
Advising & 13 & $21.3 \%$ \\
Intervention/Early Alert & 25 & $41.0 \%$ \\
Supplemental Instruction & 21 & $34.4 \%$ \\
\hline
\end{tabular}

These centers reported a mean number of students served of 3,839; however there was a large variance in the numbers reported (range of 14,910). The median was 2,750 and the mode was 400. Learning assistance directors were also asked to report the number of students in various subpopulations such as minority students and remedial/developmental students but only 11 of the 61 institutions provided data on some of these items.

\section{Section Two - Practices in Program Evaluation}

Learning assistance center directors who indicated that an effort to evaluate the center had taken place in the last two years advanced to the second part of the survey where they were presented with 21 statements about program evaluation. The directors were asked to rate their level of agreement as to whether the statement did reflect the current practice in their program evaluation, and they were also asked to rate their level 
of agreement as to whether the statement should reflect the current practice. Out of the 61 learning assistance directors who responded to the survey, 43 indicated that they had engaged in program evaluation and proceeded into this second section. Thus, about $70.5 \%$ of the respondents indicated that some form of program evaluation had occurred in their learning assistance center in the last two years; this addresses the first research question regarding the prevalence of program evaluation. The 21 statements in section two of the survey address the conditions for program evaluation both as they actually exist in the evaluation schema and as the director perceived that they should exist. The responses to these 21 statements provide additional context regarding the state of program evaluation in learning assistance centers at the community college level.

Table 6 details the results of a two-tailed t-test comparing (a) the mean of all responses to items reflecting actual practice with (b) the mean of all responses to items reflecting practices as the directors' perceive they should occur. The hypothesized mean difference between the groups was zero, and two-tailed tests were performed because differences both above and below the mean were of interest.

Table 6

t-Test: Paired Two Sample for Means Comparing Actual Practice to LAC Director's Perception

\begin{tabular}{lrr}
\hline t-Test: Paired Two & $\begin{array}{c}\text { Does Reflect } \\
\text { Actual Practice }\end{array}$ & $\begin{array}{r}\text { Should Reflect } \\
\text { Actual Practice }\end{array}$ \\
\hline Sample for Means & 3.51 & 3.90 \\
Vean & 0.51 & 0.37 \\
Standariance & 0.71 & 0.61 \\
Observations & 21 & 21 \\
t Stat & -6.68 & \\
P(T<=t) two-tail & 0.00 & \\
t Critical two-tail & 2.09 & \\
\hline
\end{tabular}


Although the t-tests did yield a statistically significant difference between the actual practice and what directors' believe should be occurring, the actual difference between the two group means was less than one half of a point on the five-point Likert scale used in the survey. The group mean for the actual practice responses was 3.51 or approximately halfway between the rating of "neutral" and "agree" on the Likert scale. The "should reflect" group mean was 3.9, which indicates that the directors had a stronger level of agreement that they should be following the practices than they actually were. The variance was smaller, 0.37 versus 0.51 , for the "should reflect group,” which would also indicate a greater level of agreement among the respondents that they should be following those practices.

Examining the differences between the "does reflect" and "should reflect" responses on the statement pairs, as shown in Table 7, provides further insights regarding differences for specific practices. The rating scale used in the survey varied from one to five, with one representing strong disagreement and five representing strong agreement. Neutral is represented by a three. The differences in the means of the responses never exceeded a score of one, or more than one step in the rating scale. 


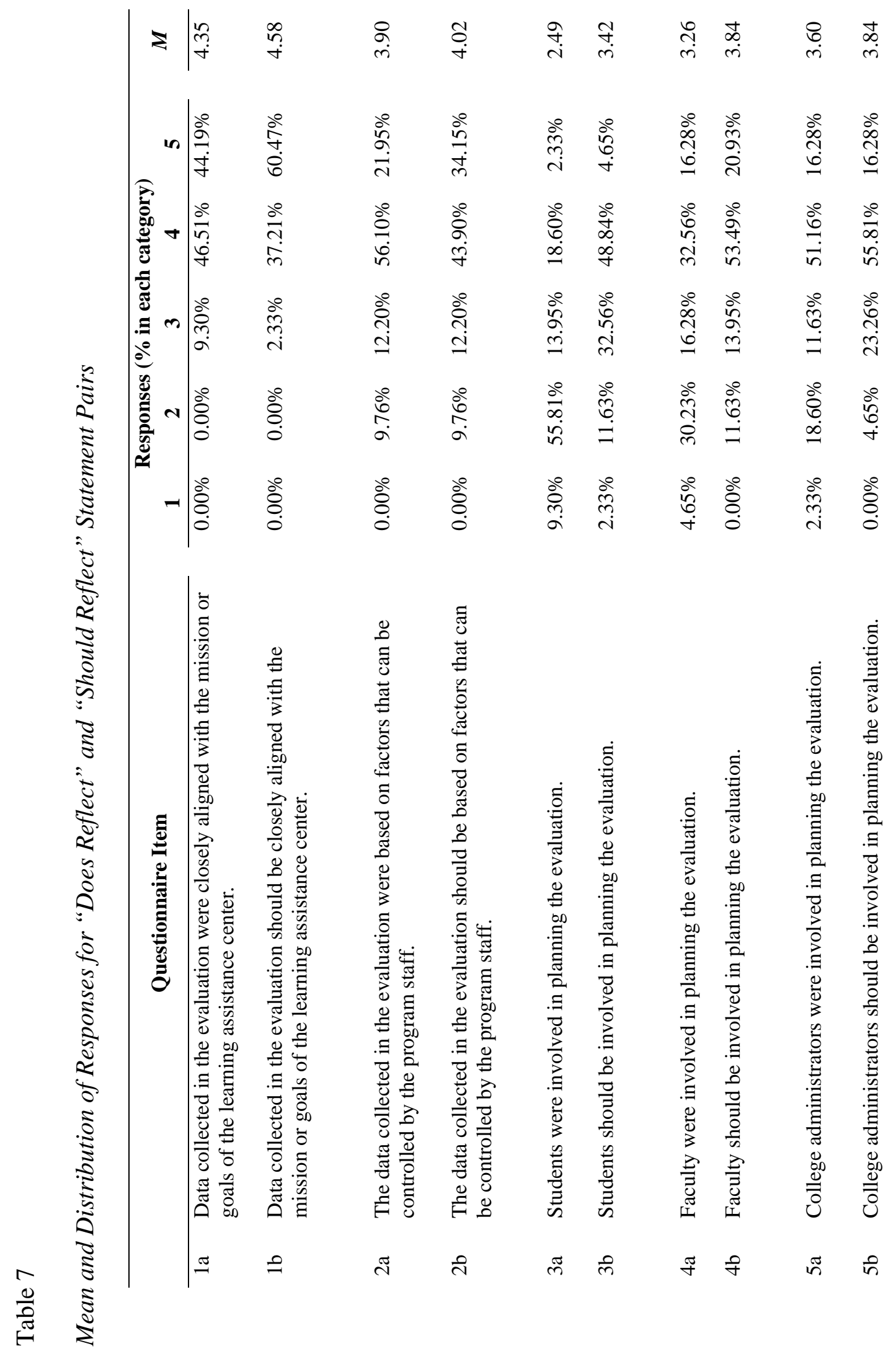




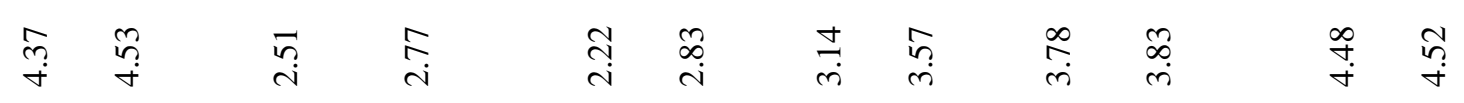

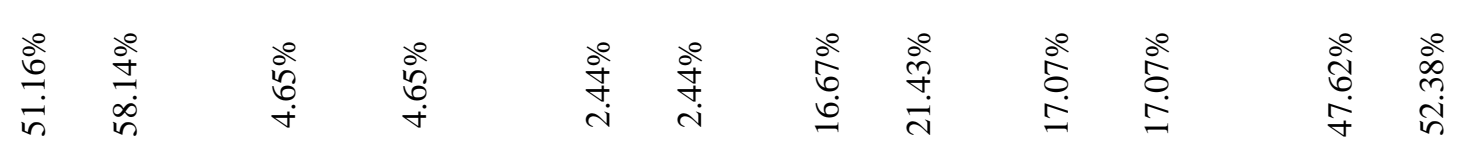

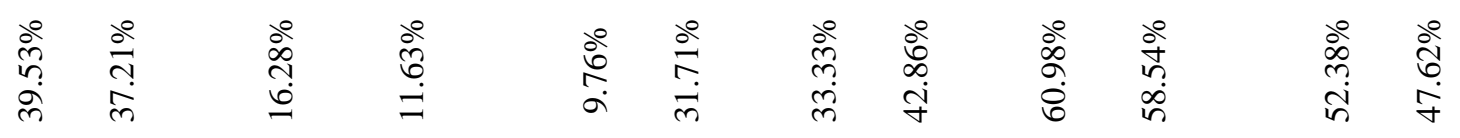

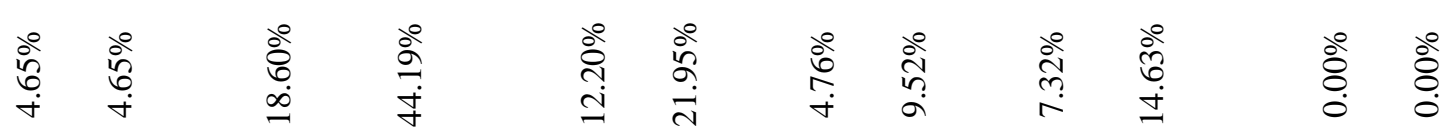

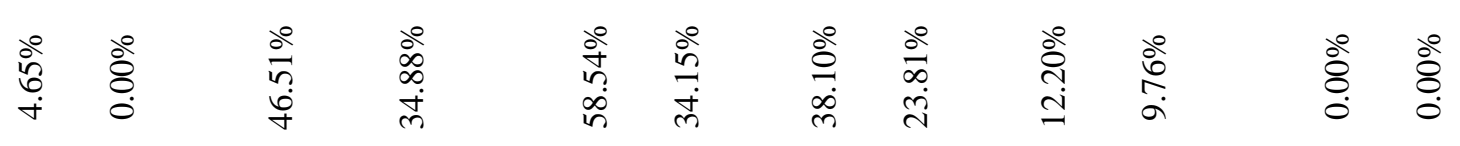

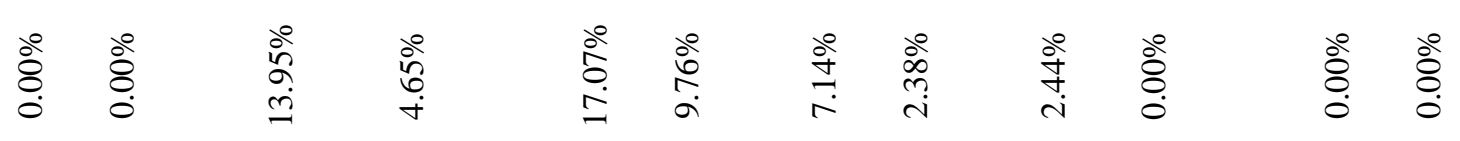

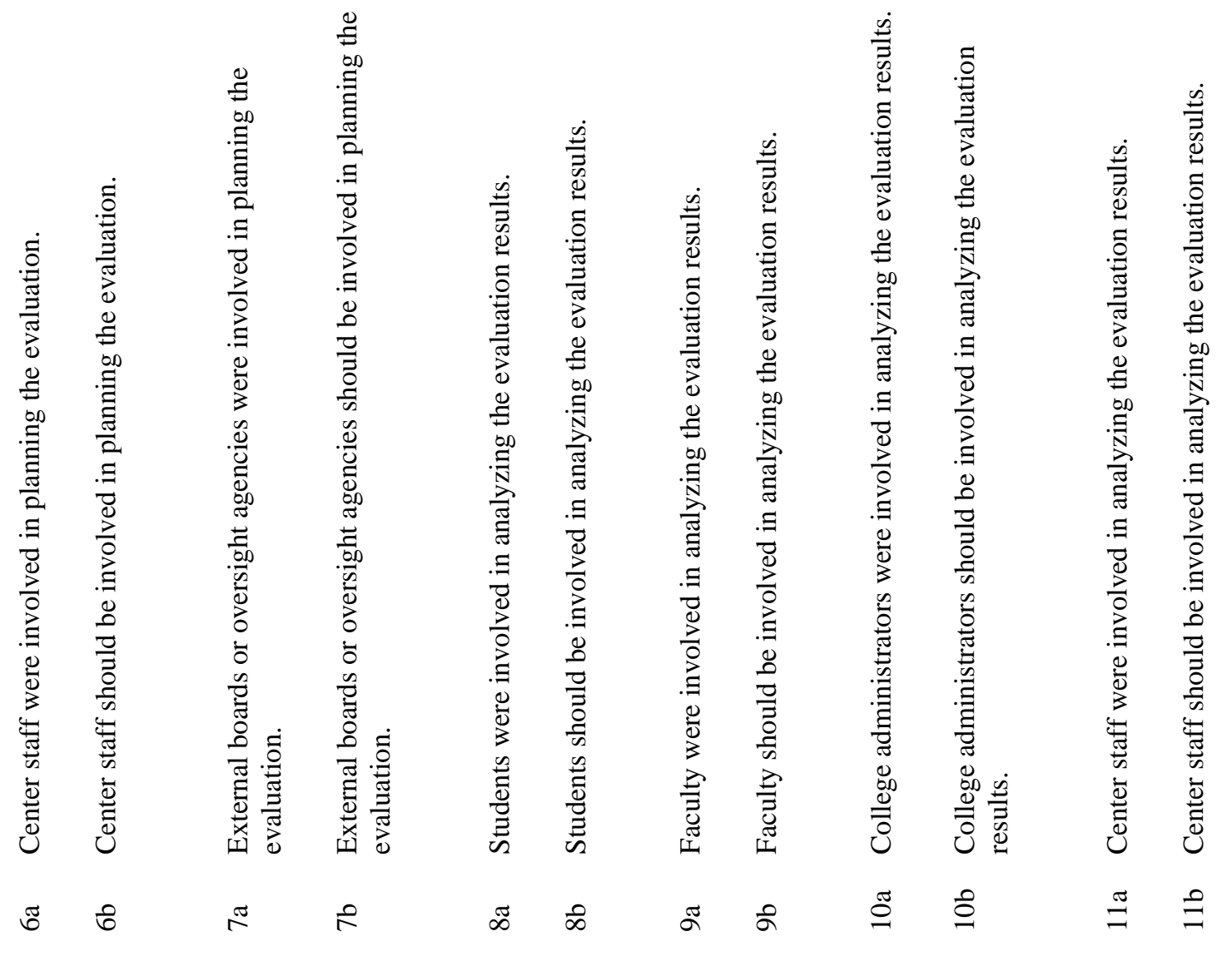




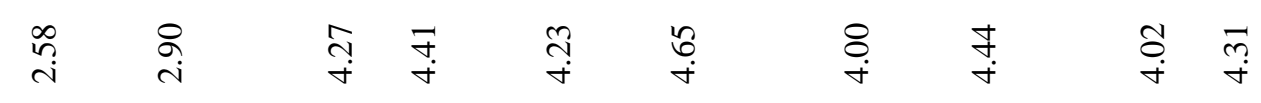

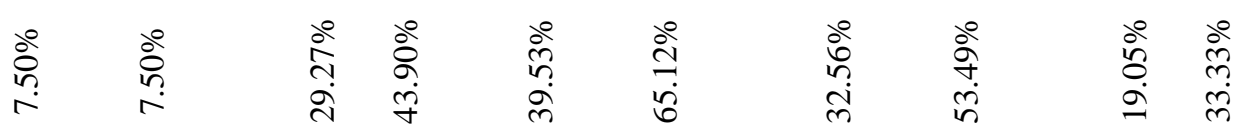

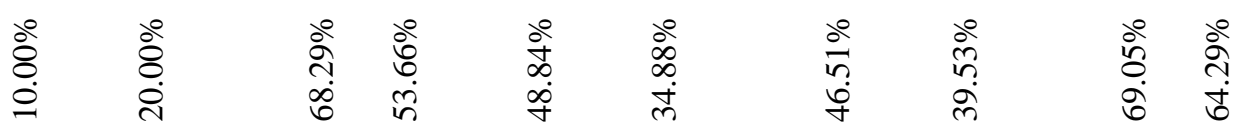

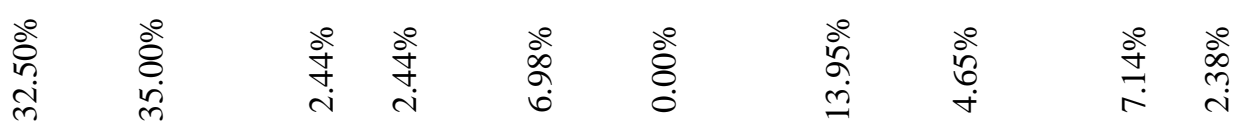

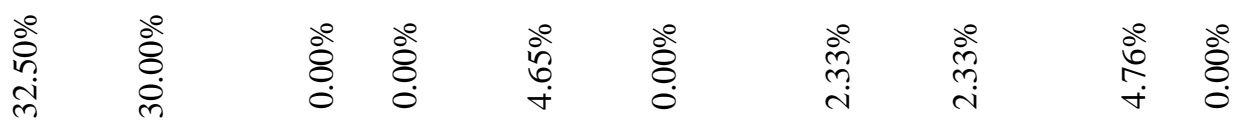

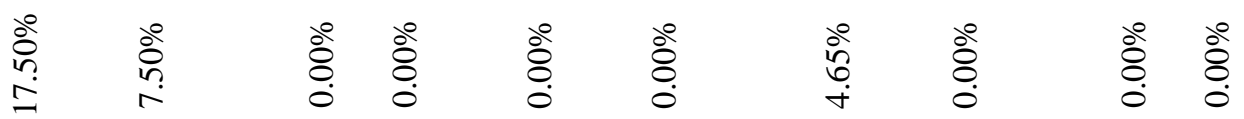

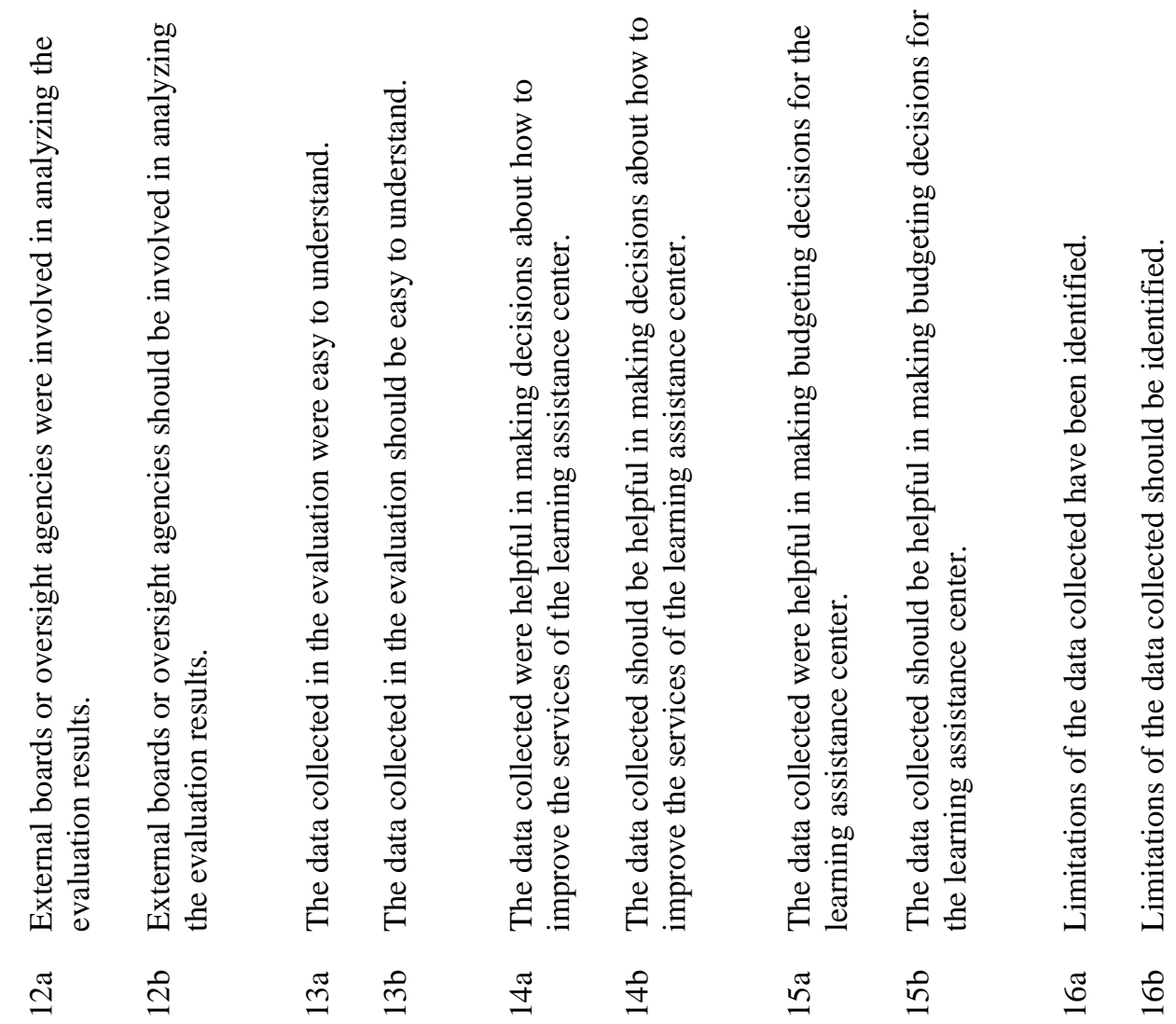




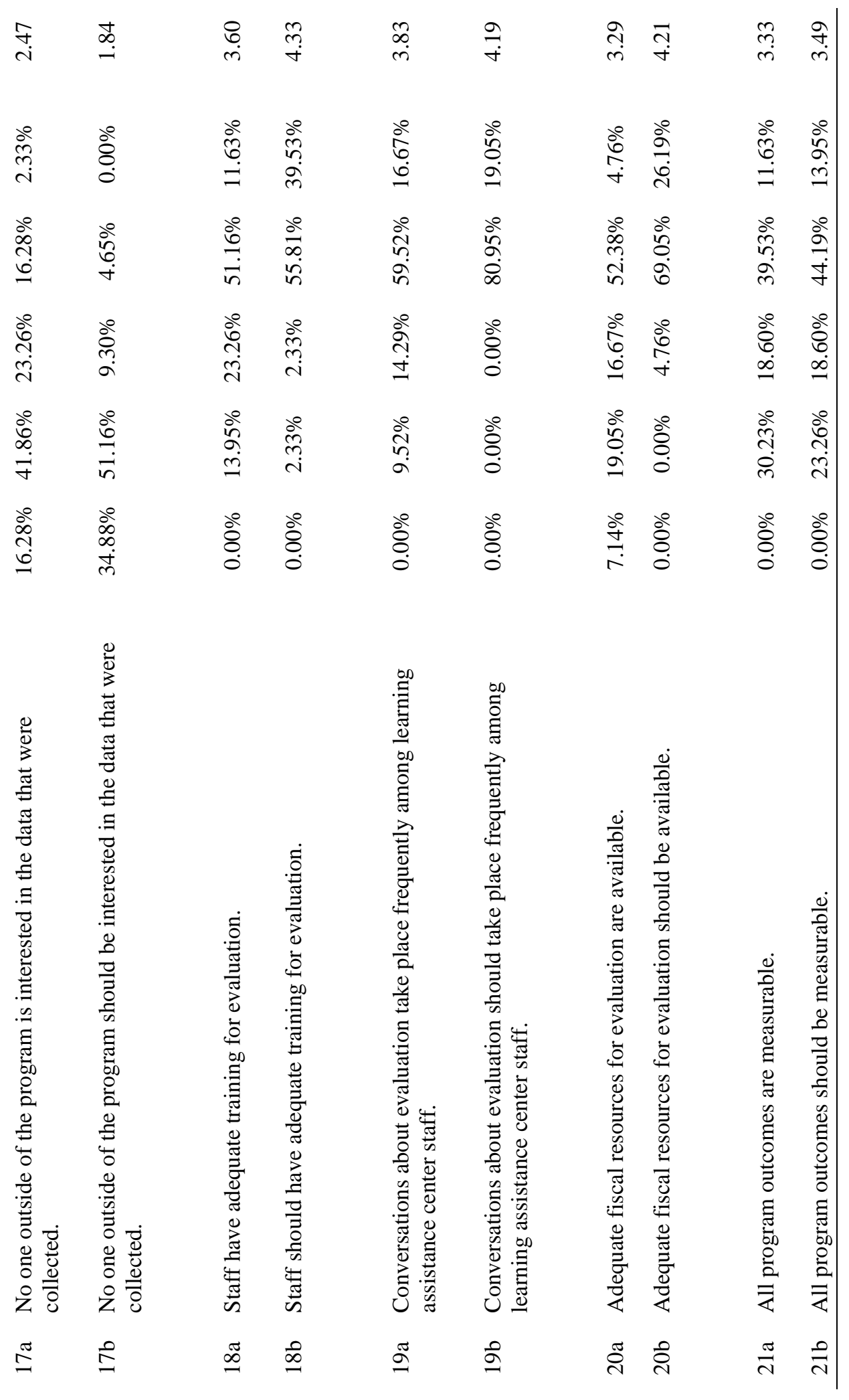


A rating above three would indicate agreement while a rating below three would indicate disagreement with the individual statements. In all but one case, the difference between “does reflect” and "should reflect” was positive, with "should reflect” having a higher rating than "does reflect.” For example, the mean for the first statement "Data collected in the evaluation were closely aligned with the mission or goals of the learning assistance center” was 4.35 for the "does reflect” group and 4.58 for the "should reflect" group. This means that, on average, the statement was true in practice in most cases and that the center directors felt that it was appropriate to be the practice. The difference, in the positive direction, might suggest that the center directors hoped for an even better alignment than that currently in practice. The one case in which the difference was in the opposite direction resulted from the fact that the statement was worded in a negative sense: "No one outside of the program is interested in the data that were collected," as opposed to the positive sense used for all other statements. Thus, the responses to this statement follow the same pattern as responses to other statements in this section of the questionnaire.

Instances where the mean for both groups is greater than three, with three corresponding to a neutral ranking on the statement, indicate that the statement is both in practice and that the center directors felt that it should be in practice which is a desirable state for program evaluation to be effective (Newcomer, Hatry, \& Wholey, 2010). Similarly, instances in which both means are below three are also desirable as that would indicate the practice is not being followed and that the center directors did not think it should be followed.

There were 16 statements, as seen in Table 8, in section two for which both means 
Table 8

Statement Pairs Where Both Means Were Greater Than Three

Paired Statements (does reflect/should reflect)

Data collected in the evaluation were/should be closely aligned with the mission or goals of the learning assistance center.

The data collected in the evaluation were/should be based on factors that can be controlled by the program staff.

Faculty were/should be involved in planning the evaluation.

College administrators were/should be involved in planning the evaluation.

Center staff were/should be involved in planning the evaluation.

Faculty were/should be involved in analyzing the evaluation results.

College administrators were/should be involved in analyzing the evaluation results.

Center staff were/should be involved in analyzing the evaluation results.

The data collected in the evaluation were/should be easy to understand.

The data collected were/should be helpful in making decisions about how to improve the services of the learning assistance center.

The data collected were/should be helpful in making budgeting decisions for the learning assistance center.

Limitations of the data collected have been/should be identified.

Staff have/should have adequate training for evaluation.

Conversations about evaluation take/should take place frequently among learning assistance center staff.

Adequate fiscal resources for evaluation are/should be available.

All program outcomes are/should be measurable. 
were above three and where the "should reflect" statement was rated higher than the “does reflect” statement. In these instances the directors seem to approve of the practices represented by those statements and are either content with their current use or would approve of seeing the relevant practice expanded or more fully implemented.

Four of the 21 statements in section two resulted in both group means being less than three, which would indicate that the statement did not reflect current practice, on average, and that the center directors did not feel that it should (see Table 9). In one of those cases, "No one outside of the program is interested in the data that were collected," the "should reflect” group mean was even lower than the "does reflect” group. This may suggest that some center directors do not feel there is enough interest in the performance of the center from those outside of the center. In the three other cases, the "should reflect” group means were higher than the “does reflect” group means but remained below three.

Table 9

Statement Pairs Where Both Means Were Less Than Three

Paired Statements (does reflect/should reflect)

External boards or oversight agencies were/should be involved in planning the evaluation.

Students were/should be involved in analyzing the evaluation results.

External boards or oversight agencies were/should be involved in analyzing the evaluation results.

No one outside of the program is/should be interested in the data that were collected. 
Finally, there was one statement, "students were involved in planning the evaluation,” where the group mean for “does reflect” and "should reflect” were on opposite sides of the neutral ranking. Also, the "should reflect” mean ranking was greater than three while the "does reflect" mean ranking was below three. This statement may provide the most interesting result of the group because it is the only one that shows discord between director perceptions of the actual practice and the desired state of practice. It indicates a desire for more student input into the planning process. However, the differences in these group means were less than one. Thus, although the directors might want to see greater student involvement than is currently the case, the difference suggests that they are not entirely unhappy with the current level of involvement. It is also interesting to note that the mean ranking for the "does reflect" statement, "Students were involved in analyzing the evaluation results," was also below three, but the mean ranking for the accompanying “should reflect” statement was also below three. Therefore, the respondents indicated that students were often not involved in either the planning of evaluation or the analysis of the results, but the respondents only felt a need for greater involvement in the planning phase.

The statements ranked highest as reflecting current practice were: "Program staff were involved in analyzing the evaluation results" (mean of 4.48), "Program staff were involved in planning the evaluation" (mean of 4.37), and "Data collected in the evaluation were closely aligned with the mission or goals of the learning assistance center" (mean of 4.35). The "should reflect” rankings associated with these statements were even higher; 4.52, 4.53, and 4.58 respectively. 
"Students were involved in analyzing the evaluation results" was the lowest ranked statement of the "does reflect" responses (mean of 2.22). This was followed by; "No one outside of the program is interested in the data that were collected" (mean of 2.47), and "Students were involved in planning the evaluation" (mean of 2.49). However, the center directors perceived that students should be involved in the planning of evaluations as evidenced by their responses to the "should reflect" statement (mean of 3.42). Recall that student employees were found to be the largest group of employees in many of these centers, often by larger margins, so it is not surprising that the center directors would desire greater involvement of students in evaluation planning. But the directors did not register the same level of support for student involvement in analyzing evaluation results as evidenced by a "should be" mean of only 2.83. This may represent a missed opportunity for the student employees to develop their skills both in providing assistance and in learning how to utilize feedback to inform their practice.

\section{Section Three - Potential Evaluation Measures}

Learning assistance center directors were asked to use a similar rating system to indicate their current use of ten different potential evaluation measures (discussed in the literature) and whether he or she thought the measure should be used in the evaluation of their program. Table 10 provides the results of a two-tailed t test comparing the mean of all responses to items reflecting "actual use" with the mean of all responses to items reflecting the "should use" responses of the directors. As before, the hypothesized mean difference between the groups was zero, and two-tailed tests were performed because differences both above and below the mean were of interest. The group mean of 3.25 for the "actual use" responses indicates that the evaluation measures in question are in use 
more often than not in learning assistance centers. The statistically significant higher mean of 3.85 for the "should use" responses indicates that the directors would like to see their use expanded beyond the current levels.

Table 10

t-Test: Paired Two Sample for Means Comparing Actual Use to LAC Directors' Preference for the Use of Potential Evaluation Measures

\begin{tabular}{lrr}
\hline t-Test: Paired Two & & \\
Sample for Means & Actual Use & Should Use \\
\hline Mean & 3.25 & 3.85 \\
Variance & 0.45 & 0.14 \\
Standard Deviation & 0.67 & 0.37 \\
Observations & 10 & 10 \\
t Stat & -5.33 & \\
P $($ T<=t) two-tail & 0.00 & \\
t Critical two-tail & 2.26 & \\
\hline
\end{tabular}

Differences between the "actual use" means and "should use” means as well as the distribution of responses are provided in Table 11. The evaluation measures ranked highest in current use were student usage statistics (mean of 4.44) and measures of student satisfaction (mean of 4.3). The center directors reported a strong desire for these measures in their "should use" ratings, as to whether these measures should be used with mean rankings that match those of the "actual use” group. The evaluation measures ranked lowest in current use were alumni perspectives (mean of 2.15), subsequent enrollment of remedial/developmental education students in college level courses (mean of 2.85), and performance of remedial/developmental education students in college level courses (mean of 3.0). However, center directors indicated a desire to use these last two measures in their responses in the "should use" group. 


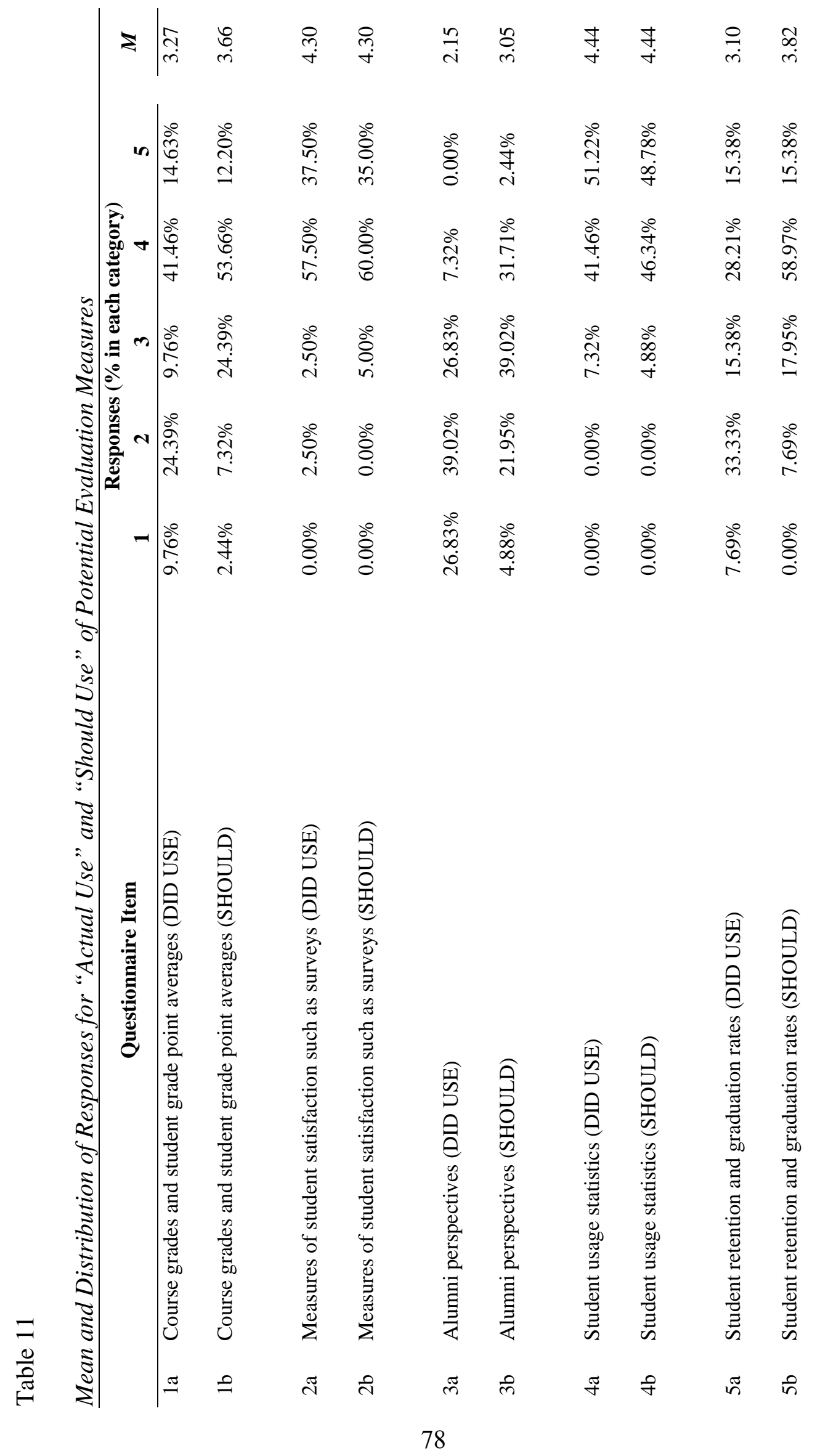




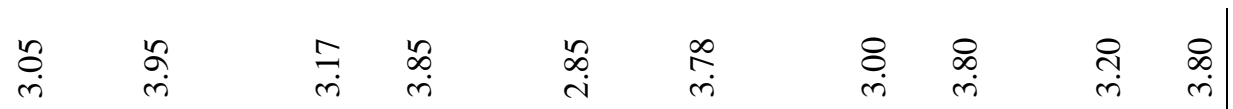

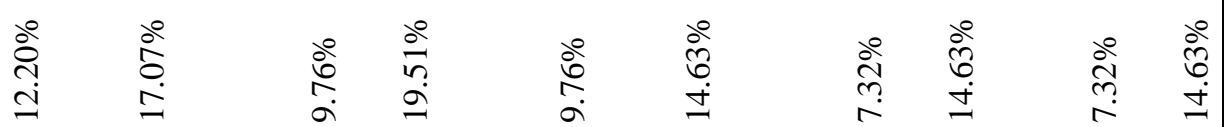

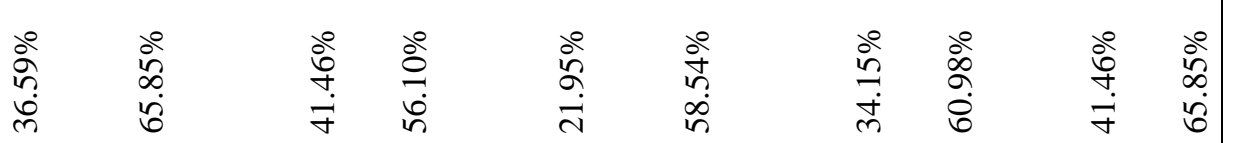

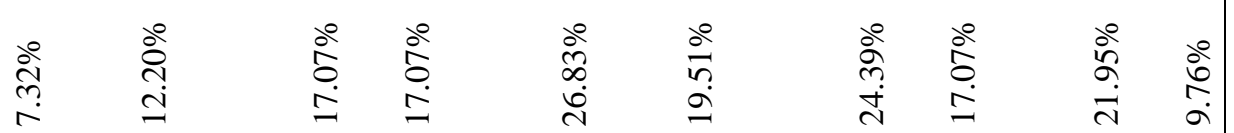

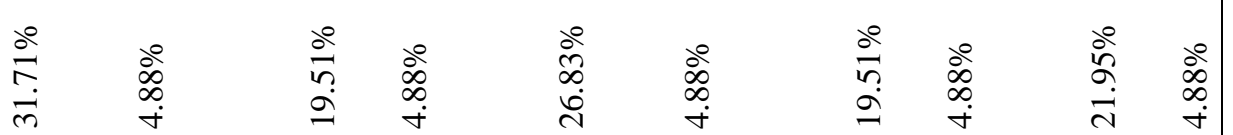

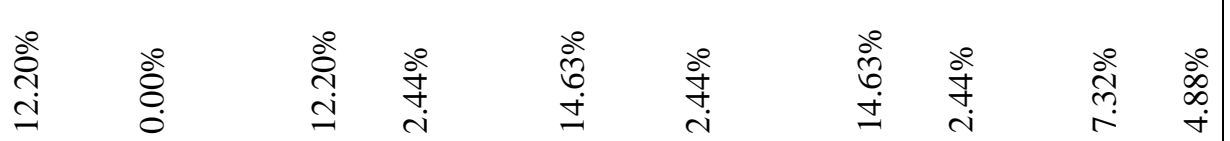

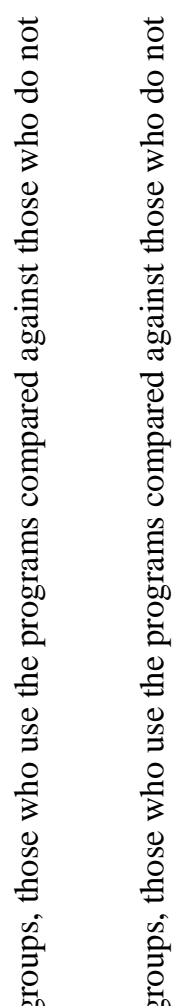

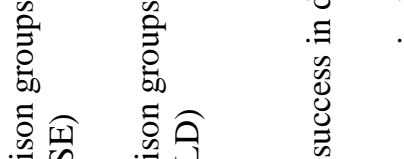

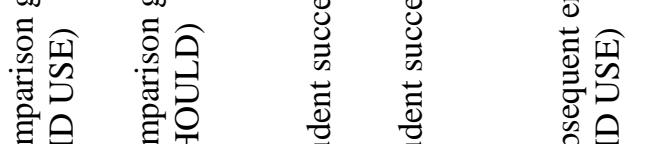

ชั
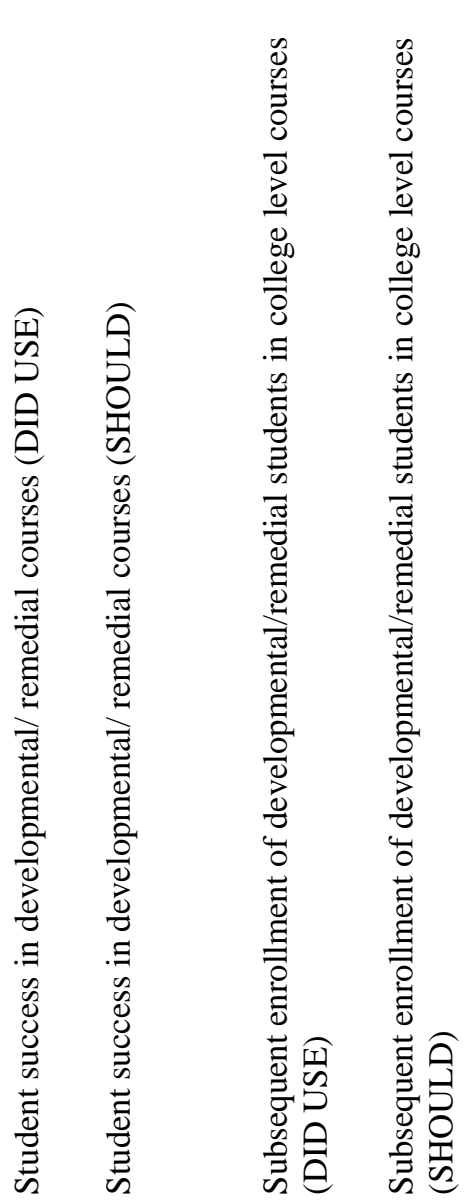

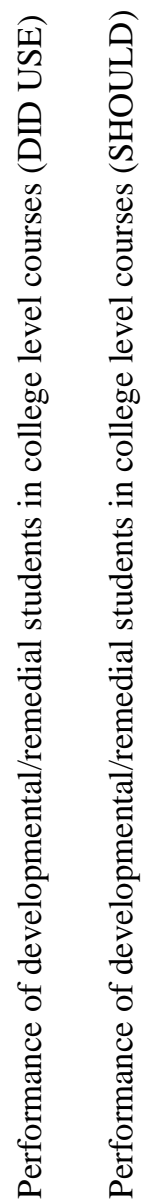

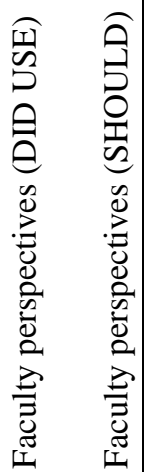

ฮี

$\approx 2$

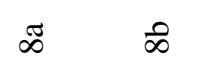

क क

華 $\stackrel{0}{-1}$ 
Both group means were greater than three, a ranking of neutral, for seven of the 10 evaluation measures (Table 12). Additionally, in the case of "performance of developmental/remedial students in college level courses," the "should use" response mean was also greater than three while the "actual use" response mean was three exactly. As in the previous section, this indicates that these eight measures are used in most cases, on average, and that the center directors feel that it is appropriate to use them. In two of these cases (the two most popular as noted above) there was no difference in the group mean rankings between the "actual use" and "should use" responses. In the six cases where there was a difference, the "should use" mean was higher than the "actual use" mean. This would suggest that the potential evaluation measures are viewed as appropriate by the center directors, on average, but that they are not being utilized at the level they desire.

\section{Table 12}

Evaluation Measures Where the "Did Use" and "Should Use" Responses Were Both Greater Than Three

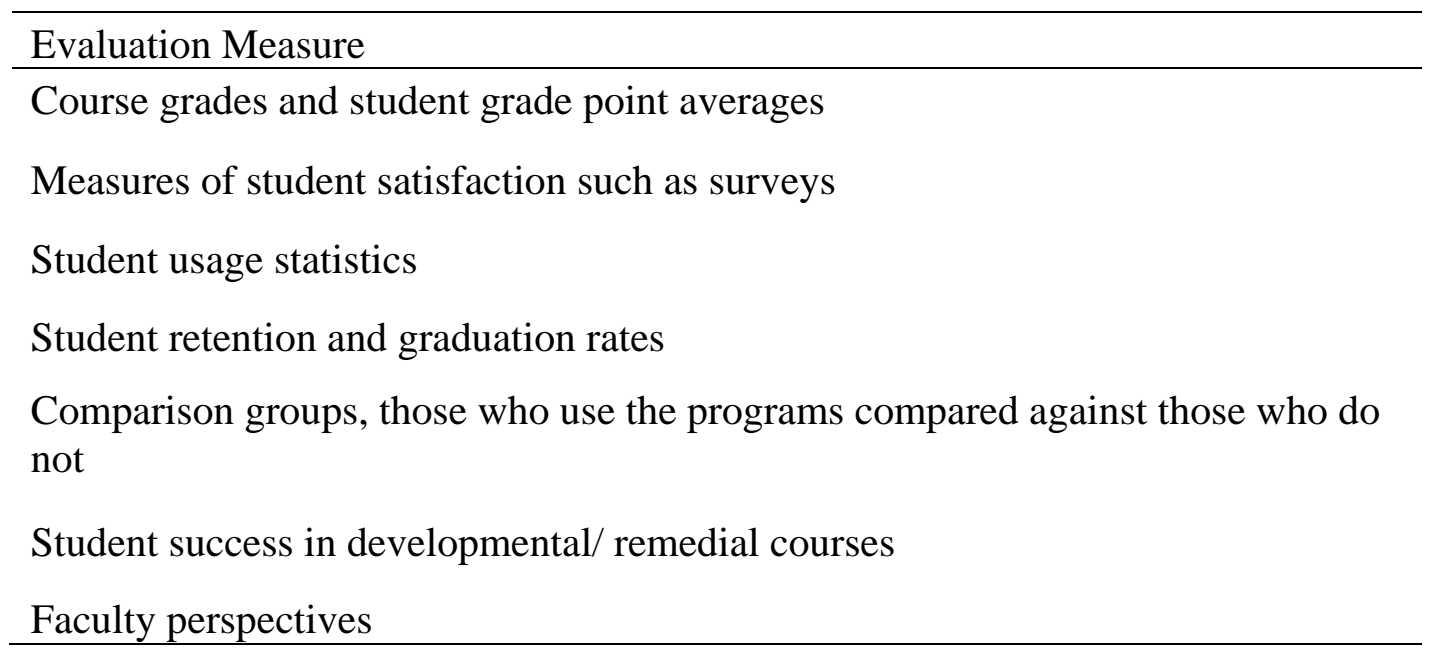


There were only two measures rated below a three for their current use: "alumni perspectives" and "subsequent enrollment of developmental/remedial students in college level courses.” The respondents indicated a higher degree of desire to include the latter but were just slightly above a neutral in rating their desire to incorporate alumni perspectives. Additional inquiry would be required to determine if this is due to the difficulty of obtaining feedback from alumni or if it is related to the content of such potential feedback. It may be beneficial to explore the use of alumni perspectives further in future studies. Furthermore, the respondents indicated a stronger desire for the use of data that track developmental/remedial students in college-level courses. Thus, future studies should explore why this measure is not utilized more often than reported in this survey.

In cases where there was a difference between the mean rankings of the "actual use" and "should use" groups, the difference was always less than one. Therefore, although the center directors may have wished to see greater use of the measures listed in the questionnaire, the responses do not suggest a high level of dissatisfaction with the current usage.

It is interesting to note that some of these measures (e.g., student usage statistics and student grade point averages) have been identified as being problematic in use for program evaluation purposes (see Chapters One and Two), but the center directors indicated that not only were they in use but that they should be used. However, tallying the number of measures in use based on the ratings in the "actual use" group, it is clear that multiple measures are being employed in each centers' program evaluation practices - a mode of seven out of the 10 measures listed in section three of the questionnaire. 
Therefore, although a particular measure may have limitations, the use of multiple measures may provide a more robust view of the effectiveness of the center in achieving its objectives. Further study would be required to determine if and how the limitations of each measure are addressed in the evaluation plans of these centers. A measure was considered to be in use, when determining this mode, if the respondent rated its actual use as either a four, agree, or as a five, strongly agree, that the measure is in use.

Two open-ended questions followed the evaluation measures section of the survey. The first asked, "If you are using measures that you do not believe are appropriate, why are they in use?” There were four responses to this question. One response indicated that the institutional research office had determined the measures and did not respond to requests for input from the learning assistance center in determining the measures. A second response referenced "institutional requirements" as the rationale, while a similar response indicated that center staff did not always get to choose the measures. The fourth response indicated new measures would follow a transition in personnel that was currently underway.

The second open-ended question was intended to capture additional evaluation measures not included in the survey: "Are there measures you would like to use but are unable to do so? If so, what measures and why are they not available for use in the evaluation of your center?” Three of the 14 responses mentioned the difficulty, discussed in earlier chapters, in tying a learning outcome to a specific intervention since students (as one respondent stated) "have varying needs, motivation, frequency in using the center, and skills that heavily influence their outcome.” Another said that "too many factors influence 'success' and tutoring is only a component and not a determinant.” 
Others listed measures that were included in the survey, such as retention, but did not have adequate resources. One director mentioned lack of funding as the missing resource, but several mentioned insufficient IT/computer support to track some evaluation measures.

The survey accomplished its goal in addressing the second research question: "What measures do learning assistance directors perceive they should be using in the evaluation of their program and what measures are actually being used? Is there a gap between the directors' perceptions of what measures they are using and what measures they should be using?” Not only did the learning assistance directors identify the use of several evaluation measures, but their responses also demonstrated that multiple measures were often employed. Overall, the respondents seemed to be in agreement with the present use of the identified measures. These responses suggest that if change were desired, it would be to see the present use of these measures increased. 


\section{CHAPTER V \\ DISCUSSION AND CONCLUSIONS}

This was an exploratory study of the prevalence and practice of program evaluation in community college learning assistance centers. A nationwide sample of 61 directors of these centers responded to a survey that collected contextual information regarding the form and function of their centers. Those directors that indicated program evaluation had taken place in the last two years, 43 of the 61 respondents, replied to two additional sections. The second section of the survey asked the directors to rate their agreement to 21 paired statements regarding program evaluation practices that were identified in the literature as being requisites for effective program evaluation. The first part of the paired statement indicated that the director felt the statement "does reflect" the practice in their center's program evaluation and the second part of the pair indicated director felt the statement "should reflect" the current practice according to his or her perspective.

The third section of the survey included another set of paired items, each pair dealing with the use of a particular evaluation measure (e.g., student grades, measures of student satisfaction, subsequent enrollment of developmental/remedial students in college-level courses). Again, respondents were asked to register their agreement that (a) the measure was actually used in the Center's evaluation and (b) the measure should be used in the Center's evaluation. This study did not seek to evaluate the effectiveness of program evaluation in these centers, only to explore its current state as reported by the 
directors of these community college learning assistance centers. The survey was designed to answer the following research questions:

1. How prevalent is the practice of program evaluation in community college learning assistance centers? That is, what proportion of community college learning assistance centers have conducted an evaluation of their services in the past two years?

2. What practices and evaluation measures do community college learning assistance directors perceive they should be using in the evaluation of their program and what practices and evaluation measures are actually being used? Is there a gap between the directors' perceptions of what practices and evaluation measures they are using and what practices and evaluation measures they should be using?

A descriptive analysis was provided in Chapter Four for each of the three sections. Additionally, t-tests were performed on the composite means of the responses to the 21 program evaluation practice statement pairs in section two and again to the 10 potential evaluation measure pairs in section three. This chapter offers an interpretive analysis of the findings, both in terms of the organizational context of the learning assistance centers led by the respondents and the ways those centers have been evaluated.

\section{Organizational Context of the Responding Centers}

The data collected in part one of the questionnaire and summarized in Chapter Four provide a sense of what services the centers provide, how the centers are funded, what the staffing patterns of the centers are. The picture that emerges suggests that learning assistance centers at community colleges, although critically important to the 
institution's goal of increasing retention and persistence (as discussed in Chapters One and Two), are often relatively small organizational units with limited capacity to carry out extensive evaluations of their work. This is evident in (a) a reliance on large numbers of part-time and student employees to provide services (b) a lack of data on special populations served in the center such as developmental/remedial students and underrepresented populations, and (c) limited control over the evaluation, or the measures used in evaluation, based on responses to the open-ended questions. Each is discussed below.

\section{Staffing}

The contextual information collected in part one of the survey seems to indicate that learning assistance centers are not considered a core operation on many campuses. Although the centers were often funded by the institutions as part of the operating budget, it is only at a level to support a largely contingent workforce of student employees and part-time staff as evidenced by the responses to the survey indicating a part-time to fulltime of staff ration of three to one and an even larger ratio of student-employees. Faculty involvement in the centers was reported as being minimal, less than one full-time and six part-time on average, and it was often the case that clerical staff were non-existent, less than one full-time and two part-time on average, in these centers. In terms of staffing, then, most centers appear to be lean operations relying primarily on part-time, contingent employees.

\section{Availability of Data}

Limited data appeared to be another factor that constrained the capacity of the learning assistance centers to carry out evaluations of their services. Many of the 
respondents were able to provide estimates of the total number of students served by the center on an annual basis, but fewer were able to provide data on subpopulations of interest such as developmental/remedial students, underrepresented populations, or students with disabilities requiring specialized services or assistance. The reasons for this are a matter of speculation. Perhaps the respondents did not report data on subpopulations because they simply were not available. Another possibility is that the data were available but not easily retrievable given the lack of clerical support (e.g., the data are available only on paper reports that must be tallied by hand.) Either case suggests that the centers are not able to address how they serve populations that community colleges and learning assistance centers specifically, deem most in need of academic support services.

\section{Limited Control}

Responses to the open-ended questions also suggested that the centers did not have a say in program evaluation measures that were used. For example, one respondent volunteered that "we do not always get to choose the measures.” Others reported that they did not have adequate resources, in the form of funding or information technology support to conduct program evaluations. This can be seen in the comments of one respondent who noted that, "We don't have a system such as Tutor Trac to pull reports" and from the observation of another who wrote that, "We do not have the computer support at this time to track subsequent registration in remedial courses or college level courses." Though the responses to the "should reflect" and "should use” statements in sections two and three of the survey indicated a desire on the part of the center directors to improve program evaluation, responses to the open-ended questions suggest that many 
of these are not in control of the evaluation and lack resources to carry it out more effectively.

\section{On the Margins?}

Responses to questions in section one of the survey instrument seem to reflect the shoestring nature of learning assistance centers, which appear to operate on the margins of the organization. Viewing the structure of a community college through the lens of Mintzberg's five-sector logo (1979), where the faculty reside in the operating core of the college and the technostructure contains institutional research and similar staff who provide technical services in a close relationship with the faculty and the administration, we would expect to find learning assistance centers in the "support staff” sector of Mintzberg's model. Learning assistance centers indeed provide services in support of the college's mission, but limited staffing, inadequate data, and (perhaps) limited control over the evaluation process suggest that that in many cases they are not considered critical to the operation of the institution. However, given the small sample of LAC directors who responded, as well as the small number who provided responses to openended queries concerning LAC operations, any conclusions drawn from the contextual data collected in this study must be viewed as tentative hypotheses that should be tested in future studies.

\section{Findings Concerning Evaluation Practices and Measures}

In response to the first research question, 43 of the 61 respondents indicated that their centers had undergone an evaluation within the last two years. An analysis of the responses to section two provides further contextual information about the program evaluation practices of these centers. As detailed in Chapter 4, the evaluations 
undertaken by the centers seemed to be based on a solid foundation with many of the "best practices" of program evaluation found in the literature, including alignment with mission/goals, stakeholder engagement, appropriate data use, and adequate resources. The directors in this study agreed that most of those practices were indeed followed, though their responses to statements about the extent to which those practices should be followed suggest that improvements can indeed be made. The item yielding the greatest discrepancy between perceptions of what is happening and what should be happening related to the inclusion of students in program evaluation planning. Survey responses indicated that students were rarely included, but that directors strongly felt that they should be included. Students were also not involved in analyzing data as part of the program evaluation process, but the directors did not indicate a desire for student involvement in that practice. Another group of stakeholders that was typically not involved (according to the survey responses) included external oversight bodies, but the directors did not express a desire for their involvement either.

Responses to the third section of the survey, which focused on 10 potential evaluation measures, suggest that the program evaluations undertaken by the learning assistance centers included, more often than not, these measures and that the LAC directors concurred that the measures were appropriate. Still, a statistically significant difference existed between the composite means of the "actual-use" and "should-use" responses, implying that the respondents would like to see an expansion of their use.

\section{Strengths and Weaknesses of LAC Program Evaluation}

Four dimensions of "best practices" in program evaluation were discussed in the literature review: alignment of evaluation with the mission and/or goals of the program 
(Berk \& Rossi, 1990; Newcomer, Hatry, \& Wholey, 2010; Yarbrough, Shulha, Hopson, \& Caruthers, 2011); inclusion of stakeholders in the design and implementation of the evaluation (Astin, 1993; Banta, Lund, Black, \& Oblander, 1996; Bryson \& Patton, 2010); appropriate data use that informs decision-making and leads to improvement (Newcomer, Hatry, \& Wholey, 2010; Poister, 2010); and, finally, adequate resources (e.g., time, money, training, etc.) to support evaluation (Hadden \& Davies, 2002).

As noted above, the findings suggest that learning assistance directors tend to agree that their evaluation practices align with these recommended best practices. Furthermore, the responses to the "should reflect" prompts were almost always higher than statements reflecting actual practice. This suggests a desire to strengthen the current alignment of evaluation practices with those practices recommended in the literature. Faculty, college administrators, and program staff were all often involved in the evaluation routine as reported in the survey.

In addition, program evaluation is not based on just one or a few evaluation measures in most cases. Instead, program evaluation typically includes at least seven different evaluation measures out of the 10 listed in the survey instrument. In the case of those measures that were reported as being in use more often than not, the respondents indicated their agreement that the measures should be in use. As in the previous section, the responses also suggested a desire to increase the current level of use.

Nonetheless, the LACs appeared to face several constraints that might limit their capacity to improve evaluations of their impact. Due to the nature of their place within the structure of the community college, learning assistance centers face some limitations in their ability to execute program evaluation effectively. For example, responses to the 
open-ended questions, discussed above, indicate that evaluation measures are sometimes selected for the center by outside parties such as the institutional research office and that the LAC staff do not have input in these measures.

A lack of fiscal and human resources, as noted above, may also impact program evaluation in different ways. A lack of clerical staff can affect the ability of a center to keep records of the number of students served, how much time was spent with the students, or what activities took place during the time the students spent in the center. The use of part-time and student employees to provide services limits the amount of staff time that can be spent on planning program evaluations and analyzing data that are collected due to the limited time those staff members are present in the center.

Furthermore, there are a limited number of permanent and/or supervisory staff available to provide training and engage the contingent staff in professional development activities. A lack of technology to assist in the collection and tracking of data was also noted.

\section{Implications for Practice}

There are several implications for practice that can be identified based on the findings. These implications relate to (a) the engagement of students in both program evaluation planning and in the analysis of program evaluation data, (b) the need to ensure that LACs are reaching students who are core to the mission of the community college, and (c) the need for additional resources to more effectively carry out program evaluation. Each of these implications is discussed in further detail below.

\section{Student Engagement in Program Evaluation}

The greatest concern of the learning assistance center directors who participated in this study entailed their perception that students were not as involved in evaluation 
planning as they should be. The "does reflect" response to the inclusion of students in analyzing the evaluation data was also low, but the directors did not express a desire to see students involved in that process. The lack of students in both planning and analysis, and the lack of interest in including students in the analysis stage, are problematic for both the program evaluation planning and execution. They also have consequences for the successful delivery of services in the learning assistance center.

Students occupy two distinct roles in these learning assistance centers; they are the clients whom the centers were designed to assist but, as found in the responses to the survey, they are also (in many cases) the employees charged with delivering the services of the center to their peers. How do student employees determine their effectiveness, and how do they use this knowledge to improve their practice? As previously discussed, it is important to identify the key intended users in a program evaluation plan, because if those users are not informed by the results of program evaluation, with the intention of leading to program improvement, then the process is "often not worth the cost of the evaluation” (Newcomer, Hatry, \& Wholey, 2010, p. 6). If the staff who are delivering the services are not informed by the program evaluation process, then that significantly lessens the impact of the evaluation. Wholey (2010) further posited that a successful evaluation process depends on the intended users being able to use the information gathered in enhancing and improving services. This appears to be an area where improvements need to be made; if student employees are not engaged in program evaluation, they are unlikely to shape their interactions with peer clients on the basis of program evaluation results. 
The literature has also addressed the student-client stakeholder perspective in the program evaluation process, highlighting the need to communicate the purposes and intended outcomes of the evaluation process to students (National Research Council, 2001). Such communication is intended to demonstrate that the students are valued and respected. Furthermore, the National Research Council (2001) argues that assessment activities should be embedded in everyday program activities as a way of providing an authentic and on-going view of the student's performance when he or she is fully engaged in those activities, as opposed to external assessment activities that may fail to fully engage the student. However, note that this would also require not just the involvement of the student as a client but also the involvement of the student as a service provider when the center relies on student employees to deliver its services.

\section{Attention to Student Clients with Greatest Needs}

Most of the respondents did not provide data on the number of students in various sub-populations such as minority, remedial/developmental, and students with special needs. Though it is true that the centers serve the general student population and not just underprepared students (Arendate, 2010), analyzing center work with and impacts on these student subpopulations is crucial. If the centers are not collecting such data then they are missing an opportunity to evaluate the efforts of the center in addressing populations that, as noted earlier, require extra attention (McCabe, 2000). To be sure, the centers may face real obstacles in collecting these data. For example, the coordinator of the division that supports students with special needs at the author's prior institution did not allow that area's data to be tracked in other systems. As a consequence, there were no data available to the director of the learning assistance center on the number of special 
needs students who received services each year. A desire to track the performance of remedial/developmental students into college-level courses and determine their success in those courses was noted in the responses to section three of the survey, yet many centers did not provide a response to the item regarding the number of remedial/developmental students served in the learning assistance center. Such students have to be identified before they can be tracked.

The urgency of doing this is highlighted by the high ratings the respondents gave to the item dealing with the alignment of evaluation data with the mission and goals of the center: "Data collected in the evaluation were closely aligned with the mission or goals of the learning assistance center.” Ironically, though, they tended to indicate that they did not have data on the participation of remedial/developmental students, suggesting that many of these learning assistance centers may not identify the support of remedial/ developmental students explicitly in their mission statements or goals. If, as Arendale (2010) points out, lowered admissions standards and “open-door” admissions policies were reasons for the expansion of learning assistance centers, then it is surprising that the alignment of the goals and outcomes of learning assistance centers are not more closely tied to serving students in need of developmental education. The same would be true for underrepresented populations such as minorities, low-income students, or students with special needs (i.e., those receiving services under Section 504 of the Rehabilitation Act or the Americans with Disabilities Act [ADA]). Data on student services, participation rates, and outcomes are likely collected for compliance reporting under Section 504 and ADA, so it is surprising that more respondents were not able to provide data on the number of students served. Furthermore, considering the large 
amount of remediation that takes place at the institutions hosting these learning assistance centers, and considering the unique needs of the underrepresented populations, more attention to the function of learning assistance centers in supporting these students is certainly warranted. Poister (2010) warns of goal displacement if staff members are asked to address measures that are not aligned with program goals. If learning assistance centers decide to focus attention on their role in supporting these populations, they will need to address it in both the mission/goals of the centers and in the evaluation of the centers.

\section{Resources for Effective Program Evaluation}

Expertise in research methodology and availability of information technology that would support the work of LAC staff and/or institutional research staff in conducting program evaluation would help to address concerns identified in the literature and in comments from the respondents. The literature has criticized the failure of some evaluation plans to address intervening variables such as student motivation, because seeking assistance is often a student's decision and not required (Simpson, Hynd, Nist, \& Burrell, 1997). Additionally, differences in student preparation levels are typically not addressed when comparing the performance of students receiving assistance to those who do not. Use of propensity scores could be implemented to address such criticisms in an evaluation plan but only if the data, skills, and information technology resources required to carry out such techniques are available. Cohen and Brawer (1996) expressed concern that community colleges lacked the institutional research capacity to perform this work. LAC staff, especially the part-time and student-employee staff, likely lack the time and training to effectively use more sophisticated techniques and interpret the resulting data. One 
LAC director responded, "I would love to factor in a predictability of success score in order to measure student outcomes more connected to learning center influences. Students have varying needs, motivation, frequency in using the center, and skills that heavily influence their outcomes.”

\section{Future Directions}

The responses to the survey, and especially to some of the individual items in sections two and three, also produced several interesting findings worth further discussion and future inquiry. Learning assistance centers appear to rely heavily on parttime staff and student employees. Do these staff and student employees have sufficient time to spend on evaluation activities and discussions? Is there a constant turnover of the staff providing the majority of the services and if so, how is improvement in service developed and sustained? Are those same staff still there when the relevant evaluation data is collected and analyzed?

Respondents indicated that they used several different measures in their evaluations, but additional study would be required to know more about how they use these measures. Do LAC leaders expect that growth in a measure over time is attributable to the services received in the learning assistance center as opposed to other variables such as student preparation level, amount of time spent studying, and classroom instruction? The literature review in Chapter Two also identified concerns that some evaluation measures are used only because the data needed to report them are readily available and that some of these measures do not address more concepts (such as student learning) that are difficult to measure (Zarkesh \& Beas, 2004). Therefore, future studies should examine what LAC staff members actually learn from the evaluation data that are 
collected. How do they implement change based on what they learn? Do they require additional training and support in interpreting the data or implementing changes in their method of delivering services? The survey accomplished its goal of determining the measures in use, but this study did not address the effectiveness of the evaluation plans in use. That is a matter for future inquiry.

Another possibility for future research lies in the potential role that evaluation plays in the relationship between the learning assistance center and the institution. Program evaluation could reduce the marginalization observed in these centers by providing college administrators with data that inform budgeting and staffing decisions. When this researcher reviewed the websites of the institutions to determine the existence of a learning assistance center, it was not uncommon to find a "center" that consisted of a computer lab with a variety of math and writing drill programs. Measures of student satisfaction, such as surveys, would likely provide evidence to the administration and budget office that students find value in receiving personal attention in the learning assistance center (as opposed to the impersonal assistance of online tutorials). These results could justify the support of professional development opportunities for center staff, and they could help in determining appropriate staffing levels as well as the proper location and hours of service for the center. But this will only be accomplished if evaluation is a living and breathing process. If data collected in evaluations are simply placed in a binder and forgotten, administrative decisions impacting the operation of the center will likely be based on anecdotes or on another area in the college more effectively demonstrating its need over that of the learning assistance center. 
The Joint Committee on Standards for Educational Evaluation (Yarbrough, Shulha, Hopson, \& Caruthers, 2011) stated that program evaluation leads to improvement in a program. Decision-making should be based on the program evaluation process. Fortunately, most respondents indicated that data from their evaluation were useful in the budgeting process and in making decisions about how to improve the services of the learning assistance center. Case studies examining how the data are used for these purposes could benefit those directors and institutions that are struggling with tying decision-making practices to the collection and interpretation of program evaluation data.

Program evaluation is taking place in learning assistance centers and is based on multiple measures that are collected in an environment aligned with the "best practices" of program evaluation generally speaking. The next step for the field is to examine how these evaluations are implemented and how they impact the performance of the learning assistance centers in supporting all students and in supporting students considered to be "at-risk." This would enable the field to make significant progress in promoting student retention and completion and in producing the skilled workforce needed to fill the growing number of “middle-level” jobs (Holzer \& Lerman, 2007) that require postsecondary training but not a four-year degree. Expanding the knowledge base of program evaluation in learning assistance centers will also enable proponents to better advocate for the needs of their centers when tough budget decisions need to be made.

Recall that determining the effectiveness of program evaluation within learning assistance centers was not a goal for this study. Further study would be required to gain a better understanding of how the multiple measures currently used are incorporated into the evaluation schema, how they may complement each other, how they might conflict 
with each other, and how their limitations are addressed. Similarly, further study is needed to understand how the practices detailed in section two of the survey are actually carried out. For example, there was a high level of agreement among the respondents that program staff were involved in planning the evaluation. What is not known is how the staff were involved, who participated and at what level, and whether the staff felt they had the adequate training and preparation to participate in the planning exercise. However, this study did provide a foundation for future exploration of these topics by describing the current state of program evaluation in the community college learning assistance centers that participated in the study. 


\section{REFERENCES}

Adelman, C. (1996, October 4). The truth about remedial work: It's more complex than windy rhetoric and simple solutions suggest. Chronicle of Higher Education. p. A56.

American Evaluation Association (AEA), (2004). Guiding principles for evaluators. Retrieved from website: http://www.eval.org/publications/aea06.GPBrochure.pdf

Alexander, P., \& Jetton, T. (2000). Learning from text: A multidimensional and developmental perspective. In M. Kamil, P. Mosenthal, P. Pearson, \& R. Barr (Eds.), Handbook of reading research (Vol. III, pp. 285-310). Mahwah, NJ: Erlbaum.

Arendale, D. R. (2007). A Glossary of developmental education and learning assistance terms. Journal of College Reading \& Learning, 38(1), 10-34.

Arendale, D. R. (2010). Access at the crossroads: Learning assistance in higher education (ASHE Higher Education Report, Vol. 35, No. 6). San Francisco: Jossey-Bass.

Argyris, C. (1995). Action science and organizational learning. Journal of Managerial Psychology, 10(6), 20-26.

Astin, A. W. (1993). Assessment for Excellence. Phoenix, AZ: The Oryx Press.

Aud, S., Hussar, W., Planty, M., Snyder, T., Bianco, K., Fox., M., . . . Drake, L. (2010). The condition of education 2010 (NCES 2010-028). Retrieved from http://nces.ed.gov/pubs2010/2010028.pdf

Bailey, T. T., Jacobs, J. J., Jenkins, D. D., \& Leinbach, T. T. (2003, April). Community colleges and the equity agenda: What the record shows. Paper prepared for the AACC national conference, Dallas, TX. Retrieved from http://ccrc.tc.columbia.edu/ media/k2/attachments/community-colleges-equityagenda.pdf.

Banta, T. W., Lund, J. P., Black, K. E., \& Oblander, F. W. (1996). Assessment in practice: Putting principles to work on college campuses. San Francisco: JosseyBass. 
Becherer, J. J., \& Becherer, J. (1995). Programs, services, and activities: A survey of the community college landscape. In S. R. Helfgot (Ed.), Promoting student success in the community college (New Directions for Student Services, Vol. 69, pp. 6375. San Francisco: Jossey-Bass.

Berk, R. A., \& Rossi, P. H. (1990) Thinking about program evaluation. Newbury Park, CA: Sage.

Bolman, L. G., \& Deal, T. E. (2013). Reframing organizations: Artistry, choice, and leadership (5 ${ }^{\text {th }}$ ed.) (pp. 75). San Francisco, CA: Jossey-Bass

Boughan, K. (1996). The academic impact of student support services program participation in fiscal year 1996. Program evaluation (Report No. PE97-2). Largo, MD: Prince George’s Community College, Office of Institutional Research and Analysis. Retrieved from ERIC database. (ED423917).

Boylan, H. R. (1985). The effectiveness of developmental education programs. Research in Developmental Education, 2(2), 1-4.

Boylan, H., Bliss, L., \& Bonham, B. (1997). Program components and their relationship to student performance. Journal of Developmental Education, 20(3), 2-8.

Boylan, H., \& Saxon, D. (2001). The cost of remedial education in higher education. Journal of Developmental Education. 25(2), 2-8.

Bragg, D. D. (1995). Assessing postsecondary vocational-technical outcomes: What are the alternatives?. Journal of Vocational Education Research, 20(4), 15-39.

Burd, S., \& Field, K. (2004, October 1). Choices limited for needy students. Chronicle of Higher Education Retrieved from http://chronicle.com/article/Choices-Limitedfor-Needy/10364

Burke, J. C. (1997). Performance-funding indicators: Concerns, values, and models for two- and four-year colleges and universities. Retrieved from ERIC database. (ED407910).

Burke, J. C., \& Minassians, H. (2001). Linking state resources to campus results: From fad to trend--The fifth annual survey. Retrieved from ERIC database. (ED456781).

Burke, J. C., \& Minassians, H. P. (2004). Implications of state performance indicators for community college assessment. In A. M. Serban, \& J. Friedlander (Eds.), Developing and implementing assessment of student learning outcomes (New Directions for Community Colleges, No. 126, pp. 53-64). San Francisco: JosseyBass. 
Burke, J. C., \& Serban, A. M. (Eds.). (1998). Performance funding for public higher education: Fad or trend? (New Directions for Institutional Research, No. 97). San Francisco: Jossey-Bass.

Chung, C. J. (2005). Theory, practice, and the future of developmental education. Journal of Developmental Education, 28(3), 2-4, 6, 8, 10, 32-33.

Closson, R. B. (1996). The learning society: How shall community colleges respond? Community College Review, 24, 3-18.

Clark-Thayer, S. (Ed.) (1995). NADE self-evaluation guides: Models for assessing learning assistance/developmental education programs. Clearwater, FL: H\&H Publishing Company.

Clymer, C. (1978, March). A national survey of learning assistance evaluation: Rationale, techniques, problems. Long Beach, CA: Annual Meeting of the Western College Reading Association. Retrieved from ERIC database. (ED155603).

Cohen, A. M., \& Brawer, F.B. (1996). The American community college (3rd ed.). San Francisco: Jossey-Bass.

Complete College America. (2010). Set a state completion goal. Retrieved from http://www.completecollege.org/docs/CCA\%20Essential\%20Steps\%20Set\%20A \%20State\%20Completion\%20Goal.pdf

Consolvo, C. (2002). Building student success through enhanced, coordinated student services. Journal of College Student Development, 43(2), 284-287.

Dellow, D. A., \& Romano, R. M. (2002). Editor's choice: Measuring outcomes: Is the first-time, full-time cohort appropriate for the community college? Community College Review, 30(2), 42-54.

Ehrenberg, R. G. (2012). American Higher Education in Transition. Journal of Economic Perspectives, 26(1), 193-216.

Ewell, P. T. (1985). Transformation leadership for improving student outcomes. (NCHEMS Monograph 6). Boulder, CO: National Center for Higher Education Management Systems. Retrieved from ERIC database. (ED310653).

Favero, M. D. (2002). Linking administrative behavior and student learning: The learning centered academic unit. Peabody Journal of Education, 77(3), 60-84.

Fey, C. J., \& Carpenter, D. S. (1996). Mid-level student affairs administrators: management skills and professional development needs. NASPA Journal, 33, 218231. 
Field, K. (2009, May 22). A year of college for all: What the president's plan would mean for the country. Chronicle of Higher Education. Retrieved from http://chronicle.com/article/A-Year-of-College-for-All-/44386

Ford, D. Y., \& Trotman, M. F. (2000). The Office for Civil Rights and nondiscriminatory testing, policies, and procedures: Implications for gifted education. Roeper Review, 23,109-112.

Gansemer-Topf, A. M., \& Schuh, J. H. (2003). Instruction and academic support expenditures: An investment in retention and graduation. Journal of College Student Retention, 5(2), 135.

Gibbs, P. (2001). Higher education as a market: A problem or solution? Studies in Higher Education, 26(1), 85-94.

Gilardi, S., \& Guglielmetti, C. (2011). University life of non-traditional students: Engagement styles and impact on attrition. Journal of Higher Education, 82(1), 33-53.

Glenn, D., Laster, J., Miller, M. H., \& Schmidt, P. (2010, March 28). When budget cuts loom. Chronicle of Higher Education. Retrieved from http://chronicle.com/article/When-Budget-Cuts-Loom/64867/

Gray, P. J. (1997). Viewing assessment as an innovation: Leadership and the change process. In P. J. Gray \& T. W. Banta (Eds.), The campus-level impact of assessment: Progress, problems, and possibilities (New Directions for Higher Education, No. 100, pp. 5-15). San Francisco: Jossey-Bass.

Grossman, P. (2001). Making accommodations - The legal world of students with disabilities. Academe-Bulletin of the AAUP, 87(6), 41-46.

Hadden, C., \& Davies, T. G. (2002). From innovation to institutionalization: The role of administrative leadership in the assessment process. Community College Journal of Research and Practice, 26, 243-260.

Hadwin, A. F., \& Winne, P. H. (1996). Study strategies have meager support: A review with recommendations for implementation. The Journal of Higher Education, 67, 692-715.

Hebel, S. (2010, March 14). State cuts are pushing public colleges into peril. Chronicle of Higher Education. Retrieved from http://chronicle.com/article/In-Many-StatesPublic-Higher/64620/

Higbee, J. L., Katz, R. E., \& Schultz, J. L. (2010). Disability in higher education: Redefining mainstreaming. Journal of Diversity Management, 5(2), 7. 
Hofer, B., Yu, S., \& Pintrich, P. (1999). Teach college students to be self-regulated learners. In B. Zimmerman \& D. H. Schunk (Eds.), Self-regulated learners and academic achievement: Theory, research, and practice (pp. 57-85). New York: Springer-Verlag.

Holzer, H. J., \& Lerman, R. I. (2007). America’s forgotten middle-skills jobs: Education and training requirements in the next decade and beyond. Retrieved from http://www.nationalskillscoalition.org/assets/reports-/americasforgotten middleskilljobs_2007-11.pdf

Hossler, D., Ziskin, M., \& Gross, J. P. K. (2009). Getting serious about institutional performance in student retention: Research-based lessons on effective policies and practices. About Campus, 13(6), 2-11. doi: 10.1002/abc.271

How Far States Have to Go to Meet Obama's College-Completion Goal. (2010, February 24). Chronicle of Higher Education. Retrieved from http://chronicle.com/article/Chart-How-Far-States-Have-to/64361/

Kalivoda, K. S. (2003). Creating access through universal instructional design. In J. L. Higbee, D. B., Lundell, \& I. M. Duranczyk (Eds.), Multiculturalism in developmental education (pp. 25-34). Minneapolis: University of Minnesota, General College, Center for Research on Developmental Education and Urban Literacy. Retrieved from http://www.cehd.umn.edu/crdeul

Kelderman, E. (2011, January 24). State spending on higher education edges down, as deficits loom. Chronicle of Higher Education. Retrieved from “http://chronicle.com/article/State-Spending-on-Colleges/126020/”

Kirkland, T. P. (1997). Assessment planning: The $\mathrm{P}$ in planning is for politics. Community College Journal of Research and Practice, 21, 289-296.

Kulik, J., \& Kulik, C. L. (1991). Developmental instruction: An analysis of the research. Boon, NC: National Center for Developmental Education.

Kulik, C. L., Kulik, J., \& Schwalb, B. (1983). College programs for high-risk and disadvantaged students: A meta-analysis of findings. Review of Educational Research, 53, 397-414.

Lewis, A. C. (2004, January). More college prep. Education Digest, 69(5), 70-71.

Lewis, L., \& Farris, E. (1996). Remedial education at higher education institutions in fall 1995 (NCES 97-584). Retrieved from http://nces.ed.gov/pubs/97584.pdf.

Marcotte, D., Bailey, T., Borkoski, C., \& Kienzl, G. S. (2005). The returns to education at community colleges: Evidence from the National Education Longitudinal Survey. Educational Evolution and Policy Analysis, 27, 157-175. 
Maxwell, M. (1979). Improving student learning skills: A comprehensive guide to successful practices and programs for increasing the performance of underprepared students. San Francisco: Jossey Bass.

Maxwell, M. (1997). What are the functions of a college learning assistance center? Retrieved from ERIC database. (ED413031).

McCabe, R. H. (2000). No one to waste: A report to public decision-makers and community college leaders. Washington, D.C.: Community College Press. Retrieved from ERIC database. (ED448813).

McCarron, G., \& Inkelas, K. (2006). The gap between educational aspirations and attainment for first-generation college students and the role of parental involvement. Journal of College Student Development, 47(5), 534-549.

Mercer, D. (2010). Illinois Turns Away 27,000 for Financial Aid. Community College Week, 22(22), 32.

Midwestern Higher Education Compact (2009). Completion-based funding for higher education. Retrieved from http://www.arkleg.state.ar.us/education/HigherEd/ Statistics/0209completionbasedfunding.pdf

National Education Summit on High Schools (2005). Getting it done: Ten steps to a state action agenda. Retrieved from http://www.nga.org/cms/home/nga-center-forbest-practices/center-publications/page-edu-publications/col2-content/maincontent-list/getting-it-done-ten-steps-to-a-s.html

National Research Council (2001). Knowing what students know: The science and design of educational assessment. Washington, DC: National Academy Press.

Neuburger, J. (1999, January). Research \& recommendations for developmental education and/or learning assistance programs in the state of New York. Retrieved from http://www.umkc.edu/cad/nade/nadedocs/nyclsa02.htm

Newcomer, K. E., Hatry, H. P., \& Wholey, J. S. (2010). Planning and Designing Useful Evaluations. In J. S. Wholey, H. P. Hatry, \& K. E. Newcomer. (3rd ed.), Handbook of practical program evaluation (pp. 5-29). San Francisco: JosseyBass.

Oakes, J. Two cities' tracking and within-school segregation. In Lagemann, E. C. \& Miller, L. P. (Eds.), Brown V. Board of Education: The challenge for today's schools (pp. 81-90). New York: Teachers College Press. 
Oudenhoven, B. (2002). Remediation at the community college: Pressing issues, uncertain solutions. In T. Bers \& H. Calhoun (Eds.), Next steps for the community college (New Directions for Community Colleges, No. 117, pp. 35-44). San Francisco: Jossey-Bass.

Palmer, R. T., Davis, R. J., Moore, J. L., \& Hilton, A. A. (2010). A Nation at Risk: Increasing College Participation and Persistence Among African American Males to Stimulate U.S. Global Competitiveness. Journal of African American Males in Education, 1, 105-110.

Palomba, C., \& Banta, T. W. (1999). Assessment essentials: Planning, implementing, and improving assessment in higher education. San Francisco, CA: Jossey-Bass.

Patton, M. (2008). Sup wit Eval Ext? In M. T. Braverman, M. Engle, M. E. Arnold, \& R. A. Rennekamp (Eds.), Program evaluation in a complex organizational system: lessons from cooperative extension (New Directions for Evaluation, No. 120, pp. 101-115). San Francisco: Jossey-Bass

Parsad, B., Lewis, L., \& Greene, B. (2003). Remedial education at degree-granting postsecondary institutions in Fall 2000. Statistical analysis report. Washington, D.C.: National Center for Education Statistics. Retrieved from ERIC database. (ED482370).

Perin, D. (2004). Remediation beyond developmental education: The use of learning assistance centers to increase academic preparedness in community colleges. Community College Journal of Research \& Practice, 28(7), 559.

Peterson, M. W., \& Einarson, M. K. (2001). What are colleges doing about assessment? The Journal of Higher Education, 72(6), 630-669.

Poister, T. (2010). Monitoring program outcomes. In J. S. Wholey, H. P. Hatry, \& K. E. Newcomer. (Eds.), Handbook of Practical Program Evaluation ( $3^{\text {rd }}$ ed., pp. 100124). San Francisco: Jossey-Bass.

Provasnik, S., \& Planty, M. (2008). Community colleges: Special supplement to The Condition of Education 2008. Statistical analysis report (NCES 2008-033). Washington, DC: National Center for Education Statistics. Retrieved from ERIC database. (ED502349).

Robert, E. R., \& Thomson, G. (1994). Learning assistance and the success of underrepresented students at Berkeley. Journal of Developmental Education, 17(3), 4. 
Romano, C. R., Hanish, J., Phillips, C. \& Waggoner, M. D. (2010). The new normal: Senior student affairs officers speak out about budget cutting. In L. Varlotta, \& B. C. Jones (Eds.), Student affairs budgeting and financial management in the midst of fiscal crisis (New Directions for Student Services, No. 129, pp. 59-70).

Roueche, J. E., Roueche, S. D., \& Ely, E. E. (2001). Pursuing excellence: The community college of Denver. Community College Journal of Research and Practice, 25, 517-537.

Safarik, L., \& Getskow, V. (1997). ERIC review - Blending the voices: Differing perspectives on the community college. Community College Review, 25(1), 69-82.

Schmid, C., \& Abell, P. (2003). Demographic risk factors, study patterns, and campus involvement as related to student success among Guilford Technical Community College students. Community College Review, 31(1), 1-16.

Schneider, M. (2010). Finishing the first lap: The cost of first year student attrition in America's four year colleges and universities. Washington, DC: American Institutes for Research. Retrieved from ERIC database. (ED512253).

Seagren, A. T. (1993). The department chair: New roles, responsibilities and challenges. Washington D. C.: George Washington University. Retrieved from ERIC database. (ED363165).

Siddle Walker, V. E. (1996). Can institutions care? Evidence from the segregated schooling of African American children. In Shujaa, M. J. (Ed.), Beyond desegregation: The politics of quality in African American schooling (pp. 209). Thousand Oaks, CA: Corwin Press.

Simpson, M. L. (2002). Program evaluation studies: Strategic learning delivery model suggestions. Journal of Developmental Education, 26(2), 2-10.

Simpson, M. L., Hynd, C. R., Nist, S. L., \& Burrell, K. I. (1997). College academic assistance programs and practices. Educational Psychology Review, 9(1), 39-87.

Skrla, L., Scheurich, J. J., Garcia, J, \& Nolly, G. (2004). Equity audits: A practical leadership tool for developing equitable and excellent schools. Educational Administration Quarterly, 40, 133-161.

Smith, J. L., \& Vellani, F. A. (1999). Urban America and the community college imperative: The importance of open access and opportunity. In R. C. Bowen \& G. H. Muller (Eds.), Gateways to democracy: Six urban community college systems (New Directions for Community Colleges, No. 107, pp. 5-13). San Francisco: Jossey-Bass. 
Spielman, F. (2010, July 29). City College to lay off 225. Chicago Sun-Times. Retrieved from http://www.suntimes.com/news/cityhall/2547902,city-colleges-cuts072910.article

Starks, G. (1989). Retention and developmental education: What the research has to say. Research \& Teaching in Developmental Education, 6(1), 21-32.

Stern, S. (2001). Learning assistance centers: Helping students through. Los Angeles, CA: University of California at Los Angeles. Retrieved from ERIC database. (ED455901).

Stone, J. R., Blackman, O. \& Lewis, M. (2010). The promise of middle-skill occupations. Techniques, 85(5), 22-25.

Stufflebeam, D. L. (2001). The metaevaluation imperative. American Journal of Evaluation, 22(2), 183.

Terenzini, P. T. (1989). Assessment with open eyes: Pitfalls in studying student outcomes. Journal of Higher Education, 60, 644-664.

Thrift, N. (2010, July 8). Defending the university. Chronicle of Higher Education. Retrieved from http://chronicle.com/blogs/worldwise/defending-theuniversity/25375

Thompson, A. R., \& Bethea, L. (1997). Faculty knowledge of disability laws in higher education: A survey. Rehabilitation Counseling Bulletin, 40(3), 166.

Tierney, W. G. (2001,). Why committees don’t work: Creating structure for change. Academe, 87(3), 25-29.

Tilsley, A. (2010, July 6). Financial pressures grow on New Jersey’s public universities. Chronicle of Higher Education. Retrieved from “http://chronicle.com/article/Financial-Pressures-Grow-on/66148/”

Tinto, V. (1993). Leaving college: Rethinking the causes and cures of student attrition ( $2^{\text {nd }}$ ed.). Chicago, IL: University of Chicago Press.

U.S. Department of Justice, Civil Rights Division. (2004, August). A guide to disability rights laws. Retrieved from the U.S. Department of Justice Web site: http://www.usdoj.gov/crt/ada/cguide.htm

Vincent, V. C. (1983). Impact of a college learning assistance center on the achievement and retention of disadvantaged students. Retrieved from ERIC database. (ED283438). 
Visor, J. M., Johnson, J. J., \& Cole, L. N. (1992). Relationship of supplemental instruction to affect. Journal of Developmental Education, 16(2), 16-18.

Walleri, D., Seybert, J. A., \& Cosgrove, J. J. (1992). What do students want? How student intentions affect institutional assessment. Community, Technical, and Junior College Journal, 62, 28-31.

Weber, D. A., \& Ehrenberg, R. G. (2009). Do expenditures other than instructional expenditures affect graduation and persistence rates in American higher education? (NBER Working Paper No. 15216). Retrieved from National Bureau of Economic Research web site: http://www.nber.org/papers/w15216

Weissman, J., Bulakowski, C., \& Jumisko, M. (1997). Using research to evaluate developmental education programs and policies. In J. Ignash (Ed.), Implementing effective policies for remedial and developmental education (New Directions for Community Colleges, No. 100, pp. 73-80). San Francisco: Jossey-Bass.

Weissman, J., Bulakowski, C., \& Jumisko, M. (1998). A study of white, black, and Hispanic students' transition to a community college. Community College Review, 26(2), 19-42.

White, L.F. (2002). Learning disability, pedagogies, and public discourse. College Composition and Communication, 53(4), 705-738.

White, W. G. Jr., \& M. L. Schnuth. (1990). College learning assistance centers: Places for learning. In R. M. Hashway (Ed.) Handbook of developmental education (pp. 155-177). New York: Praeger.

Wholey, J. S. (2010). Exploratory evaluation. In J. S. Wholey, H. P. Hatry, \& K. E. Newcomer (Eds.), Handbook of practical program evaluation. ( ${ }^{\text {rd }}$ ed., pp. 8199). San Francisco: Jossey-Bass.

Wholey, J. S., Hatry, H. P., \& Newcomer, K. E. (2010). Handbook of practical program evaluation (3rd ed.).San Francisco: Jossey-Bass.

Williams, T. E. (2002). Challenges in supporting student learning and success through student services. In T. Bers \& H. Calhoun (Eds.), Next steps for the community college (New Directions for Community Colleges, No. 117, pp. 67-76). San Francisco: Jossey-Bass.

Wirt, J., Choy, S., Grunder, A., Sable, J., Tobin, R.,Bae, Y., . . West, J. (2000). The condition of education 2000 (NCES 2000-062). Retrieved from http://nces.ed.gov/pubs2000/2000062_intro.pdf 
Yarbrough, D. B., Shulha, L. M., Hopson, R. K., and Caruthers, F. A. (2011). The program evaluation standards: A guide for evaluators and evaluation users (3rd ed.). Thousand Oaks, CA: Sage

Zarkesh, M., \& Beas, A. M. (2004). UCLA community college review: Performance indicators and performance-based funding in community colleges. Community College Review, 31(4), 62-76. 
APPENDIX A

SURVEY INSTRUMENT 


\section{Survey Instrument}

\section{Part I: Descriptive Information}

Please read and respond to the following items that provide some descriptive information of your learning assistance center.

1. Please identify the unit that the learning assistance center falls under at your institution.

Academic Affairs

Student Affairs

Other (please specify)

2. How many full-time staff members in each of the following categories are employed within your center? If someone is employed full-time by the institution but only holds a partial assignment to the center then please record him or her in the part-time section (see question three, below).

Administration/Managerial (staff whose primary function is to manage the center and its functions) Faculty (solely assigned to the center) Professional staff (staff that hold some required qualification and provide a service requiring some skill or training) Clerical/Secretarial (including student employees/volunteers) Students (students that provide tutoring/student support services, not those proving clerical/secretarial services)

3. How many part-time staff members in each of the following categories are employed within your center? If someone is employed full-time by the institution but only holds a partial assignment to the center then please record him or her in this section.

Administration/Managerial (staff whose primary function is to manage the center and its functions) Faculty (can include regular college faculty that also provide services in the center)

Professional staff (staff that hold some required qualification and provide a service requiring some skill or training) Clerical/Secretarial (including student employees/volunteers) Students (students that provide tutoring/student support services, not those proving clerical/secretarial services) 
4. What revenue sources are used to fund the learning assistance center? Please check all that apply.

Funded by institution just like any other unit; including a mix of tuition and tax revenue. Local, state, and/or federal grants. Student fees (charged to all students with tuition regardless of usage) Usage fees (paid by users and based on usage) Other (Please describe)

5. What is the approximate yearly operating budget for the learning assistance center? \$

6. Which of the following services are provided by the learning assistance center (select all that apply).

Math assistance/tutoring

Writing assistance/tutoring

Reading assistance/tutoring

Computer skills assistance/tutoring

Subject matter assistance/tutoring in subjects other than math, reading, writing, or computers

Study skills assistance (e.g., note-taking, time management, test-taking, etc.)

Services for special needs students (e.g., students who qualify for services under Section 504 or ADA)

Assistance for developmental/remedial education courses (e.g., does the center devote resources specific to dev/remedial courses)

Study Groups (e.g., study sessions that are lead by center staff or faculty)

Peer tutoring (e.g., one-on-one tutoring provided by a fellow student

Trained by the center)

Classroom Presentations (e.g., presentations on a topic of the course instructor's choice by the center staff)

Programs for students on probation

Advising

Intervention/Early Alert (e.g., programs designed to identify and provide intervention to students who are considered at-risk.)

7. Does your learning assistance center offer supplemental instruction as defined below?

Yes__ No

The International Center for Supplemental Instruction (SI) at the University of Missouri Kansas City (2012) defines SI as;

an academic assistance program that utilizes peer-assisted study sessions. SI sessions are regularly-scheduled, informal review 
sessions in which students compare notes, discuss readings, develop organizational tools, and predict test items. Students learn how to integrate course content and study skills while working together. The sessions are facilitated by "SI leaders", students who have previously done well in the course and who attend all class lectures, take notes, and act as model students.

8. Approximately how many students (unduplicated headcount) does your learning assistance center serve each academic year (i.e., in both fall and spring semesters): If unknown then please enter "unknown."

9. If known, please provide the number of students in each of the following groups typically served each academic year (i.e., in both fall and spring semesters). If unknown then please place a check in the unknown column. The sub-groups can be duplicated. For example, a 26 year old Hispanic man seeking a GED can be counted once in Non-traditional, once in Adult Ed/ESL/GED, and once in Minority.

Developmental/Remedial

Approximate number of students served

Non-traditional (Age 25 and older)

ABE/ESL/GED

Minority

Special Needs

Part 2: Program Evaluation Practices

1. Has your learning assistance center conducted an evaluation of its services at some point during the past two years? Yes

No

If yes, please proceed to the next section. If no, thank you for your participation. No further responses are required and your submission is complete.

Please read the following pairs of statements about program evaluation and indicate your level of agreement. The first statement in each set refers to the current practice at your center. The second refers to your opinion about each statement, regardless of whether it is in effect in your center. 


\begin{tabular}{|c|c|c|c|c|c|c|}
\hline & Statements about Program Evaluation & & & Neutral & \multicolumn{2}{|c|}{$\begin{array}{r}\text { Strongly } \\
\text { Agree }\end{array}$} \\
\hline 1a & $\begin{array}{l}\text { Data collected in the evaluation were } \\
\text { closely aligned with the mission or goals of } \\
\text { the learning assistance center. }\end{array}$ & 1 & 2 & 3 & 4 & 5 \\
\hline $1 \mathrm{~b}$ & $\begin{array}{l}\text { Data collected in the evaluation should be } \\
\text { closely aligned with the mission or goals of } \\
\text { the learning assistance center. }\end{array}$ & 1 & 2 & 3 & 4 & 5 \\
\hline $2 \mathrm{a}$ & $\begin{array}{l}\text { The data collected in the evaluation were } \\
\text { based on factors that can be controlled by } \\
\text { the program staff. }\end{array}$ & 1 & 2 & 3 & 4 & 5 \\
\hline $2 \mathrm{~b}$ & $\begin{array}{l}\text { The data collected in the evaluation should } \\
\text { be based on factors that can be controlled } \\
\text { by the program staff. }\end{array}$ & 1 & 2 & 3 & 4 & 5 \\
\hline 3a & $\begin{array}{l}\text { Students were involved in planning the } \\
\text { evaluation. }\end{array}$ & 1 & 2 & 3 & 4 & 5 \\
\hline $3 \mathrm{~b}$ & $\begin{array}{l}\text { Students should be involved in planning } \\
\text { the evaluation. }\end{array}$ & 1 & 2 & 3 & 4 & 5 \\
\hline $4 a$ & $\begin{array}{l}\text { Faculty were involved in planning the } \\
\text { evaluation. }\end{array}$ & 1 & 2 & 3 & 4 & 5 \\
\hline $4 \mathrm{~b}$ & $\begin{array}{l}\text { Faculty should be involved in planning the } \\
\text { evaluation. }\end{array}$ & 1 & 2 & 3 & 4 & 5 \\
\hline $5 a$ & $\begin{array}{l}\text { College administrators were involved in } \\
\text { planning the evaluation. }\end{array}$ & 1 & 2 & 3 & 4 & 5 \\
\hline $5 b$ & $\begin{array}{l}\text { College administrators should be involved } \\
\text { in planning the evaluation. }\end{array}$ & 1 & 2 & 3 & 4 & 5 \\
\hline $6 a$ & $\begin{array}{l}\text { Center staff were involved in planning the } \\
\text { evaluation. }\end{array}$ & 1 & 2 & 3 & 4 & 5 \\
\hline $6 \mathrm{~b}$ & $\begin{array}{l}\text { Center staff should be involved in planning } \\
\text { the evaluation. }\end{array}$ & 1 & 2 & 3 & 4 & 5 \\
\hline $7 \mathrm{a}$ & $\begin{array}{l}\text { External boards or oversight agencies were } \\
\text { involved in planning the evaluation. }\end{array}$ & 1 & 2 & 3 & 4 & 5 \\
\hline
\end{tabular}




\begin{tabular}{|c|c|c|c|c|c|c|}
\hline $7 b$ & $\begin{array}{l}\text { External boards or oversight agencies } \\
\text { should be involved in planning the } \\
\text { evaluation. }\end{array}$ & 1 & 2 & 3 & 4 & 5 \\
\hline 8a & $\begin{array}{l}\text { Students were involved in analyzing the } \\
\text { evaluation results. }\end{array}$ & 1 & 2 & 3 & 4 & 5 \\
\hline $8 b$ & $\begin{array}{l}\text { Students should be involved in analyzing } \\
\text { the evaluation results. }\end{array}$ & 1 & 2 & 3 & 4 & 5 \\
\hline $9 a$ & $\begin{array}{l}\text { Faculty were involved in analyzing the } \\
\text { evaluation results. }\end{array}$ & 1 & 2 & 3 & 4 & 5 \\
\hline $9 b$ & $\begin{array}{l}\text { Faculty should be involved in analyzing } \\
\text { the evaluation results. }\end{array}$ & 1 & 2 & 3 & 4 & 5 \\
\hline $10 \mathrm{a}$ & $\begin{array}{l}\text { College administrators were involved in } \\
\text { analyzing the evaluation results. }\end{array}$ & 1 & 2 & 3 & 4 & 5 \\
\hline $10 \mathrm{~b}$ & $\begin{array}{l}\text { College administrators should be involved } \\
\text { in analyzing the evaluation results. }\end{array}$ & 1 & 2 & 3 & 4 & 5 \\
\hline $11 \mathrm{a}$ & $\begin{array}{l}\text { Center staff were involved in analyzing the } \\
\text { evaluation results. }\end{array}$ & 1 & 2 & 3 & 4 & 5 \\
\hline 11b & $\begin{array}{l}\text { Center staff should be involved in } \\
\text { analyzing the evaluation results. }\end{array}$ & 1 & 2 & 3 & 4 & 5 \\
\hline $12 \mathrm{a}$ & $\begin{array}{l}\text { External boards or oversight agencies were } \\
\text { involved in analyzing the evaluation } \\
\text { results. }\end{array}$ & 1 & 2 & 3 & 4 & 5 \\
\hline $12 b$ & $\begin{array}{l}\text { External boards or oversight agencies } \\
\text { should be involved in analyzing the } \\
\text { evaluation results. }\end{array}$ & 1 & 2 & 3 & 4 & 5 \\
\hline $13 a$ & $\begin{array}{l}\text { The data collected in the evaluation were } \\
\text { easy to understand. }\end{array}$ & 1 & 2 & 3 & 4 & 5 \\
\hline $13 b$ & $\begin{array}{l}\text { The data collected in the evaluation should } \\
\text { be easy to understand. }\end{array}$ & 1 & 2 & 3 & 4 & 5 \\
\hline $14 a$ & $\begin{array}{l}\text { The data collected were helpful in making } \\
\text { decisions about how to improve the } \\
\text { services of the learning assistance center. }\end{array}$ & 1 & 2 & 3 & 4 & 5 \\
\hline
\end{tabular}


14b The data collected should be helpful in

$1 \quad 2$

$3 \quad 4 \quad 5$
making decisions about how to improve the services of the learning assistance center.

15a $\begin{array}{llllll}\text { The data collected were helpful in making } & 1 & 2 & 3 & 4 & 5\end{array}$ budgeting decisions for the learning assistance center.

15b The data collected should be helpful in $\quad \begin{array}{llllll}1 & 2 & 3 & 4 & 5\end{array}$ making budgeting decisions for the learning assistance center.

16a $\begin{array}{lllllll}\text { Limitations of the data collected have been } & 1 & 2 & 3 & 4 & 5\end{array}$ identified.

16b Limitations of the data collected should be $\begin{array}{llllll}1 & 2 & 3 & 4 & 5\end{array}$ identified.

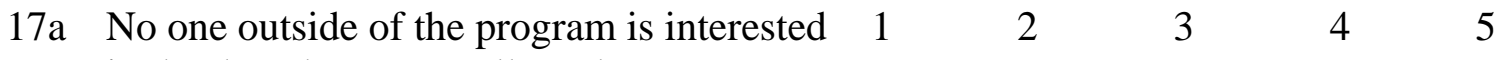
in the data that were collected.

17b $\begin{aligned} & \text { No one outside of the program should be } \\ & \text { interested in the data that were collected. }\end{aligned}$

18a Staff have adequate training for evaluation. $\begin{array}{lllllll}1 & 2 & 3 & 4 & 5\end{array}$

18b Staff should have adequate training for $\quad \begin{array}{llllll}1 & 2 & 3 & 4 & 5\end{array}$ evaluation.

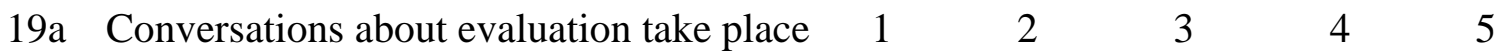
frequently among learning assistance center staff.

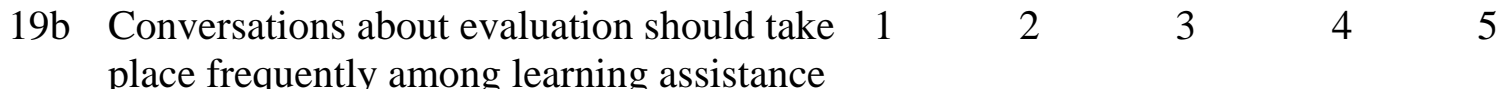
center staff.

20a Adequate fiscal resources for evaluation are available.

20b $\begin{array}{lllllll} & \text { Adequate fiscal resources for evaluation } & 1 & 2 & 3 & 4 & 5\end{array}$ should be available. 


\begin{tabular}{|c|c|c|c|c|c|c|}
\hline $21 \mathrm{a}$ & All program outcomes are measurable. & 1 & 2 & 3 & 4 & 5 \\
\hline $21 b$ & $\begin{array}{l}\text { All program outcomes should be } \\
\text { measurable. }\end{array}$ & 1 & 2 & 3 & 4 & 5 \\
\hline
\end{tabular}

Part 3: Potential Evaluation Measures in the Learning Assistance Center

Below are pairs of statements related to 10 potential evaluation measures. The first statement for each measure refers to the current use and the second refers to your opinion about whether it SHOULD be used, regardless of whether it is or is not used currently.

\begin{tabular}{|c|c|c|c|c|c|c|}
\hline & Potential Evaluation Measures & & & Neutral & \multicolumn{2}{|c|}{$\begin{array}{r}\text { Strongly } \\
\text { Agree }\end{array}$} \\
\hline $1 \mathrm{a}$ & $\begin{array}{l}\text { Course grades and student grade point } \\
\text { averages (DID USE) }\end{array}$ & 1 & 2 & 3 & 4 & 5 \\
\hline $1 b$ & $\begin{array}{l}\text { Course grades and student grade point } \\
\text { averages (SHOULD) }\end{array}$ & 1 & 2 & 3 & 4 & 5 \\
\hline $2 \mathrm{a}$ & $\begin{array}{l}\text { Measures of student satisfaction such as } \\
\text { surveys (DID USE) }\end{array}$ & 1 & 2 & 3 & 4 & 5 \\
\hline $2 b$ & $\begin{array}{l}\text { Measures of student satisfaction such as } \\
\text { surveys (SHOULD) }\end{array}$ & 1 & 2 & 3 & 4 & 5 \\
\hline За & Alumni perspectives (DID USE) & 1 & 2 & 3 & 4 & 5 \\
\hline $3 b$ & Alumni perspectives (SHOULD) & 1 & 2 & 3 & 4 & 5 \\
\hline $4 a$ & Student usage statistics (DID USE) & 1 & 2 & 3 & 4 & 5 \\
\hline $4 b$ & Student usage statistics (SHOULD) & 1 & 2 & 3 & 4 & 5 \\
\hline $5 a$ & $\begin{array}{l}\text { Student retention and graduation rates } \\
\text { (DID USE) }\end{array}$ & 1 & 2 & 3 & 4 & 5 \\
\hline $5 b$ & $\begin{array}{l}\text { Student retention and graduation rates } \\
\text { (SHOULD) }\end{array}$ & 1 & 2 & 3 & 4 & 5 \\
\hline $6 a$ & $\begin{array}{l}\text { Comparison groups, those who use the } \\
\text { programs compared against those who do } \\
\text { not (DID USE) }\end{array}$ & 1 & 2 & 3 & 4 & 5 \\
\hline $6 b$ & Comparison groups, those who use the & 1 & 2 & 3 & 4 & 5 \\
\hline
\end{tabular}




\begin{tabular}{|c|c|c|c|c|c|c|}
\hline & $\begin{array}{l}\text { programs compared against those who do } \\
\text { not (SHOULD) }\end{array}$ & & & & & \\
\hline $7 \mathrm{a}$ & $\begin{array}{l}\text { Student success in developmental/ } \\
\text { remedial courses (DID USE) }\end{array}$ & 1 & 2 & 3 & 4 & 5 \\
\hline 7b & $\begin{array}{l}\text { Student success in developmental/ } \\
\text { remedial courses (SHOULD) }\end{array}$ & 1 & 2 & 3 & 4 & 5 \\
\hline $8 a$ & $\begin{array}{l}\text { Subsequent enrollment of } \\
\text { developmental/remedial students in } \\
\text { college level courses (DID USE) }\end{array}$ & 1 & 2 & 3 & 4 & 5 \\
\hline $8 \mathrm{~b}$ & $\begin{array}{l}\text { Subsequent enrollment of } \\
\text { developmental/remedial students in } \\
\text { college level courses (SHOULD) }\end{array}$ & 1 & 2 & 3 & 4 & 5 \\
\hline $9 a$ & $\begin{array}{l}\text { Performance of developmental/remedial } \\
\text { students in college level courses (DID } \\
\text { USE) }\end{array}$ & 1 & 2 & 3 & 4 & 5 \\
\hline $9 b$ & $\begin{array}{l}\text { Performance of developmental/remedial } \\
\text { students in college level courses } \\
\text { (SHOULD) }\end{array}$ & 1 & 2 & 3 & 4 & 5 \\
\hline 10a & Faculty perspectives (DID USE) & 1 & 2 & 3 & 4 & 5 \\
\hline $10 \mathrm{~b}$ & Faculty perspectives (SHOULD) & 1 & 2 & 3 & 4 & 5 \\
\hline
\end{tabular}

If you are using measures that you do not believe are appropriate, why are they in use?

Are there measures you would like to use but are unable to do so? If so, what measures and why are they not available for use in the evaluation of your center? 
APPENDIX B

LETTER SENT TO LEARNING ASSISTANCE CENTER DIRECTORS 


\section{Dear [LEARNING ASSISTANCE CENTER DIRECTOR];}

Learning assistance centers (LACs) such as the [NAME OF CENTER] at [NAME OF COLLEGE] provide critical student services such as tutoring, study skills instruction, math and writing assistance, and/or services for students with special needs. The work of LACs is especially important for the number of students who typically struggle the most in college, including first-generation, minority, and low-income students.

However, we know very little about how centers such as yours evaluate their work with the goal of improving services to students. It is for this reason that I seek your input in a study of whether and how learning assistance centers evaluate their programs. I am a graduate student in the Department of Education Administration and Foundations at Illinois State University, and this study is being undertaken as part of my doctoral dissertation work.

Specifically, I am requesting that you complete an online survey concerning the services provided in your center, the practices that you have employed to evaluate your services, and the criteria you have used. A detailed overview of the study's purpose and procedures, as well as of risks and benefits, is provided in the enclosed reference guide. The questionnaire, which will take 20-30 minutes to complete, can be accessed at:

\section{[URL]}

You were selected as a potential participant in this study because you are the director of a learning assistance center at a public two-year institution. I reviewed your institution's website to determine that a center such as the one you direct was in place, and I obtained your contact information from your institution's website.

Your insights will add greatly to our understanding of how learning assistance centers at community colleges evaluate their services. The National College Learning Center Association has assisted me by pre-testing the survey and I will be submitting a proposal to share my findings at their annual conference this October so you have the opportunity to help inform your colleagues by participating. Your participation will be anonymous and your responses will be confidential however.

The survey is being undertaken as part of my doctoral dissertation work at Illinois State University. Only aggregate survey results will be published in the dissertation, and the names of your center and your college will not be identified. Please see the enclosed reference guide for further information on the steps that will be taken to protect the confidentiality of your responses.

Thank you for your consideration of this request. Please feel free to contact me with any questions. You can also contact my dissertation advisor, Dr. Jim Palmer (jcpalmer@ilstu.edu). Should you have questions about your rights as a study participant and the steps undertaken to minimize the risks you will face as a participant, please feel 
free to contact and the Research Ethics \& Compliance Office at Illinois State University (309.438.2529).

Sincerely,

Doug Franklin

Doctoral Candidate

Educational Administration and Foundations

Illinois State University 